
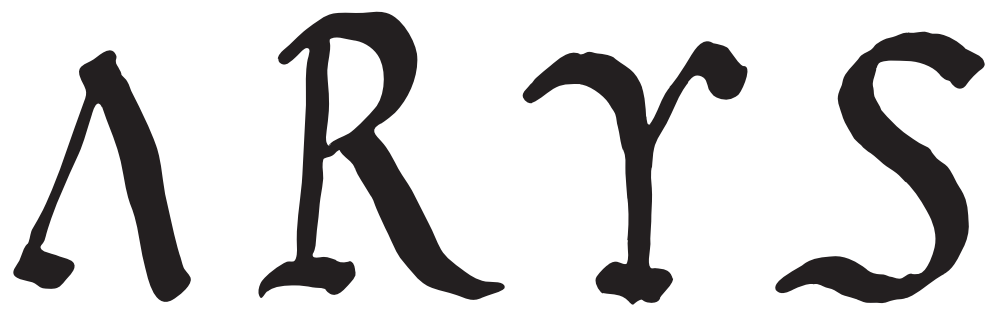

Antigüedad, Religiones y Sociedades

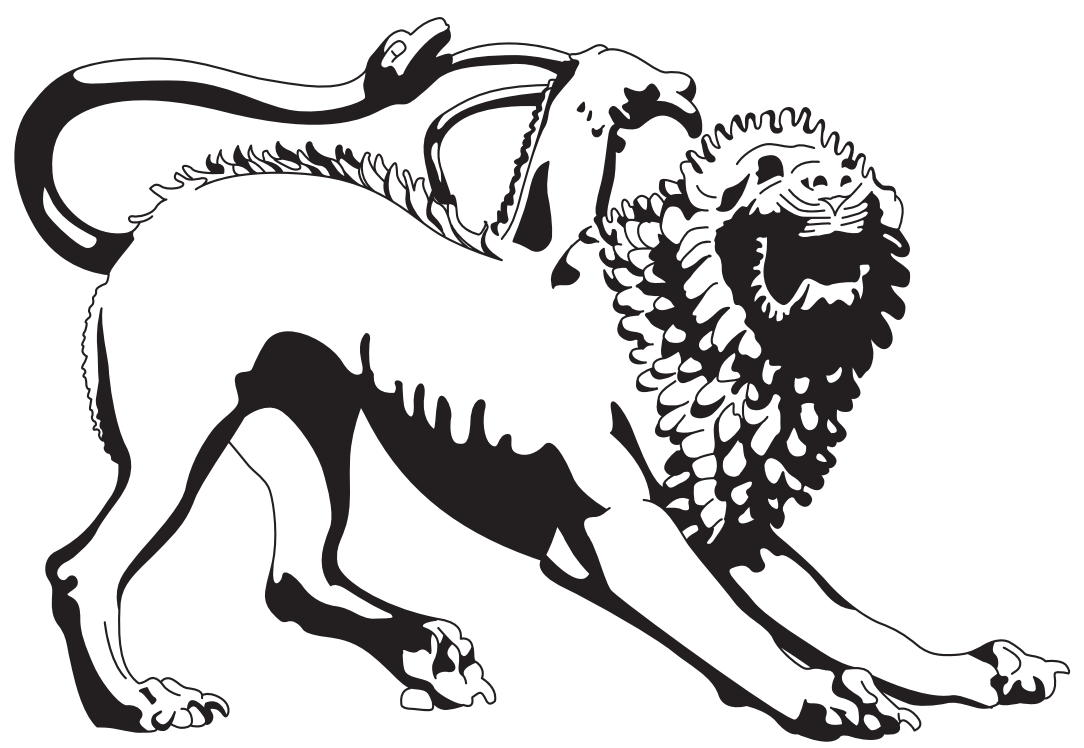

VERENDA NUMINA: TEMOR Y EXPERIENCIA RELIGIOSA EN EL MUNDO ANTIGUO 
DIRECTOR

Jaime Alvar EzQuerra

(Universidad Carlos III de Madrid)

\section{COMITÉ CIENTÍFICO \\ Radu Ardevan \\ (Universidad Babeş-Bolyai, Cluj-Napoca) JUDY BARRINGER \\ (University of Edimburg) Nicole Belayche \\ (École Pratique des hautes études à Paris) CORInne Bonnet \\ (Université Toulouse II) \\ Antonio GonZales \\ (Univ. Franche Comte) \\ María José Hidalgo de la Vega \\ (Universidad de Salamanca) \\ Rita LizzI \\ (Universita degli Studi di Peruggia) \\ Francisco Marco Simón \\ (Universidad de Zaragoza) JoHN NORTH \\ (University College London) \\ Domingo Plácido SuÁrez \\ (Universidad Complutense de Madrid) \\ Mario Torelli \\ (Università della Calabria, Cosenza; \\ Accademia Nazionale dei Lincei) \\ Henk S. Versnel \\ (University of Leiden)}

DISEÑO Y MAQUETACIÓN

Syntagmas (www.syntagmas.com)

\section{EDITA}

Dykinson S.L. (www.dykinson.com) Instituto de Historiografía Julio Caro Baroja

Universidad Carlos III de Madrid Asociación ARYS

\section{SUBSCRIPCIONES}

El precio anual de la subscripción es de $18 €$ (individual) y $30 €$ (instituciones). Para subscripciones fuera de España el precio es de $30 \$$ (individual) y $50 \$$ (instituciones).

Toda la correspondencia para subscripción, permisos de publicación, cambios de dirección $\mathrm{y}$ cualquier otro asunto debe dirigirse a:
SECRETARIO

JuAn RAMÓN CARbó García

(Universidad Católica San Antonio de Murcia)

CONSEJO DE REDACCIÓN

María del Mar Marcos Sánchez

(Universidad de Cantabria)

José Ignacio SAn Vicente GonZÁlez

De Aspuru

(Universidad de Oviedo)

Adolfo Domínguez Monedero

(Universidad Autónoma de Madrid)

Ana IrIARTE

(Universidad del País Vasco)

Rebeca Rubio Rivera

(Universidad de Castilla La Mancha)

José Luis López CAstro

(Universidad de Almería)

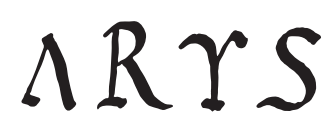

Volumen 14- 2016 - ISSN: 1575-166X

Depósito Legal M-32333-2014

ARYS: Antigüedad, Religiones y Sociedades figura indizada en CIRC, Dialnet, DICE, ERIH PLUS, Interclassica, Latindex, MIAR, RESH. Sobre la política de la revista e instrucciones para los autores, ver últimas páginas del volumen.

Reservados todos los derechos.

No se pueden hacer copias por ningún procedimiento electrónico o mecánico,

incluyendo fotocopias, o grabación magnética o cualquier almacenamiento de información y sistemas de recuperación sin permiso escrito de los escritores.

Revista ARYs

Biblioteca de la facultad de Humanidades

Universidad Carlos III de Madrid

C/ Madrid, 135

28903 Getafe (Madrid) ESPAÑA

E-Mail: imuro@db.uc3m.es

Tlfno: 916249207 


\section{$\Lambda R \Upsilon S$}

NúMERO $14-2016$

\section{VERENDA NUMINA: TEMOR Y EXPERIENCIA}

RELIGIOSA EN EL MUNDO ANTIGUO

\section{PRÓLOGO}

7 TEMOR Y EXPERIENCIA RELIGIOSA EN EL MUNDO ANTIGUO:

A MODO DE PRÓLOGO

Silvia Alfayé Villa (Universidad de Zaragoza)

\section{MONOGRÁFICO}

23 EL MIEdo Y LA RELIGIÓN: ALGUNAS REFLEXIONES GENERALES

Francisco Diez de Velasco (Universidad de La Laguna)

43 CULTO Y RITO EN CUEVAS: MODELOS TERRITORIALES DE VIVENCIA Y EXPERIMENTACIÓN DE LO SAGRADO, MÁS ALLÁ DE LA MATERIALIDAD (SS. V-II A.N.E.)

Carmen Rueda Galán y Juan Pedro Bellón Ruiz (Universidad de Jaén) 
81 CAPUT IN IECORE NON FUIT. LA 'CABEZA' DE LOS CÓNSUles POR LA SALVACIÓN DE LA REPÚBLICA

José A. Delgado Delgado (Universidad de La Laguna)

109 LOS TEMORES DEL MAGO: MIEDOS EN TORNO A LA ACCiÓN MÁGICA EN LA ANTIGUA Roma

Silvia Alfayé Villa (Universidad de Zaragoza)

153 FEARSCAPES CRISTIANOS EN EL EgIPTO TARDOANTIGUO

Clelia Martínez Maza (Universidad de Málaga)

171 Xibalba, el Lugar del Miedo: las cuevas y el inframundo de los ANTIGUOS MAYAS

Holley Moyes (University of California, Merced))

\section{VARIA}

193 UNA REFLEXIÓN SOBRE EL ORIGEN DE LA IMPORTANCIA DE LA MÚSICA EN la antigua Mesopotamia a partir de los Cilindros de Gudea A y B Daniel Sánchez Muñoz (Universidad de Granada)

\section{RECENSIONES}

223 McIntyre, Gwynaeth: A Family of Gods: The Worship of the Imperial Family in the Latin West. University of Michigan Press, Ann Arbor, 2016. Carmen Alarcón Hernández (Universidad de Sevilla) 


\title{
Culto Y RITO EN CUEVAS: MODELOS TERRITORIALES DE VIVENCIA Y EXPERIMENTACIÓN DE LO SAGRADO, MÁS ALLÁ DE LA MATERIALIDAD (SS. V-II A.N.E.) ${ }^{\mathrm{I}}$ WORSHIP AND RITUAL IN CAVES: TERRITORIAL MODELS OF LIVING AND EXPERIENCING THE SACRED BEYOND MATERIALITY (5TH-2ND C. BCE)
}

\author{
Carmen Rueda Galán ${ }^{\mathrm{II}}$ y Juan Pedro Bellón Ruiz ${ }^{\mathrm{III}}$ \\ UNIVERSIDAD DE JAÉN \\ CARUEGAL@UJAEN.ES; JBELLON@UJAEN.ES
}

\section{RESUMEN}

En el Alto Guadalquivir, entre los siglos V y II a.n.e., encontramos distintos espacios de culto en cueva, los cuales guardan una relación intrínseca con el modelo territorial en el que se insertan. A través de su análisis pretendemos señalar la heterogeneidad de sus rasgos y la variabilidad de su evolución en distintos procesos históricos locales, desde

\section{Abstract}

In the Alto Guadalquivir between the 5th and the 2nd centuries BCE we find different kinds of worship places in caves. They have an intrinsic relationship with the territorial model in which they are inserted. By analysing them, we aim to point out the heterogeneity of their features and the variability of their evolution in different local historical

\footnotetext{
${ }^{\mathrm{I}}$ Este trabajo se ha realizado dentro de los proyectos de investigación "Verenda numina: temor y experiencia religiosa en el Mundo Antiguo" (JIUZ-2014-HUM-01) del Vicerrectorado de Política Científica de la Universidad de Zaragoza, y "Lugares de culto iberos en cuevas: análisis del territorio de las Sierras de Segura y Cazorla" (2014/00043/001), Plan de Investigación de la Universidad de Jaén.

${ }^{\text {II }}$ Contratada Posdoctoral Subprograma Proyectos I+D+I, Retos a la Investigación JIN-2014 (MINECO). Instituto Universitario de Investigación en Arqueología Ibérica, Universidad de Jaén. caruegal@ujaen.es

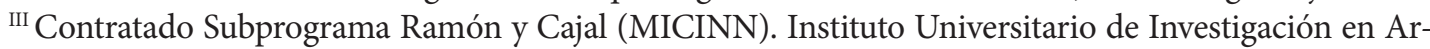
queología Ibérica, Universidad de Jaén. jbellón@ujaen.es
} 
los santuarios territoriales de Collado de los Jardines (Santa Elena) y la Cueva de la Lobera (Castellar), pertenecientes al territorio de Cástulo, pasando por el recientemente excavado santuario extraurbano de la Piedra del Águila (Orcera), al modelo urbano del oppidum de Puente Tablas (Jaén). En todos los casos se discute sobre los distintos factores relacionados con el proceso cultual, desde la movilidad, la escala de participación y la motivación que interviene en el mismo.

La heterogeneidad en las funciones y los relatos míticos recreados en las cuevas, viene discutida a través de los casos de hierofanías detectados en los santuarios expuestos, insistiendo en el papel de la cueva como espacio de mediación y conculcación emocional construido y antropizado a tal efecto, donde eventos astronómicos, como los equinoccios, juegan un papel determinante para medir los periodos de comunicación con la divinidad y realización de ritos que sancionan la medición de las estaciones y ciclos agrarios, además de formalizar el escenario de las narraciones míticas propias. processes. They range from the territorial shrines of Collado de los Jardines (Santa Elena) and Cueva de la Lobera (Castellar), in the territory of Cástulo, to the recently excavated suburban sanctuary of La Piedra del Águila (Orcera) and the urban model of the oppidum of Puente Tablas (Jaén). In all these cases we discuss the different factors related to the worship process, including mobility, the scale of participation and the motivation involved in it.

The heterogeneity of the functions and mythical stories recreated in the caves is discussed through the cases of hierophany detected at the sanctuaries in question. We emphasise the role of the cave as a place of emotional mediation built and anthropised for such a purpose. It was where astronomical events, such as the equinoxes, played a decisive role in measuring the periods of communication with the divinity and the carrying out of rites that ratified the measurement of the seasons and agrarian cycles, as well as formalising the scenario for the mythical narrations themselves.

\section{Palabras Clave}

santuarios, cueva, sociedades iberas, hierofanía, ritualidad, experiencias religiosas, paisaje sacro.

\section{KEY WORDS}

sanctuaries, cave, Iberian societies, hierophany, rituality, religious experiences, sacred landscape. 


\section{INTRODUCCIÓN}

Este trabajo plantea un análisis arqueológico de un tipo de contexto sagrado del ámbito ibero: el culto vinculado a cuevas o abrigos, que en sus diferentes variantes, como espacios urbanos o extraurbanos, nos aproxima a dinámicas rituales heterogéneas. El contexto demarca el punto de partida para la comprensión de las formas de culto, teniendo en cuenta cómo se implican este tipo de espacios en el territorio, así como su papel o función como lugares de representación aristocrática o como ámbitos de cohesión.

Metodológicamente se ha producido un salto cualitativo destacable con la inclusión del análisis de la religiosidad ibera dentro de su matriz socio-política, posibilitando su implicación y su explicación, también en términos territoriales ${ }^{1}$. Este planteamiento fuerza a la aplicación e interrelación de diferentes escalas de aproximación al registro arqueológico, que parte del análisis a nivel microespacial hasta la integración del registro votivo en la estructura de comprensión en términos territoriales. La posibilidad de articular estas diferentes escalas nos amplía las perspectivas de análisis relacionadas con las fórmulas de proyección ideológicas en las dinámicas territoriales².

1. CHAPA, T.: "Algunas consideraciones sobre el estudio de los santuarios ibéricos", Zephyrus, 43, 1990, 249-251; MOLINOS, M., ET AL.: El santuario heroico de 'El Pajarillo', Huelma, Jaén, Jaén, 1998; GRAU, I.: La organización del territorio en el área central de la Contestania Ibérica, Alicante, 2002; RUIZ, A., ET AL.: "El modelo político del pago en el Alto Guadalquivir (s. IV-III a.n.e.)", VVAA, Territori polític i territori rural durant leedat del Ferro a la Mediterránea Occidental. Actes de la Taula Rodona celebrada a Ullastret. Monografies d'Ullastret 2, Girona, 2001, 11-22; RUIZ, A., RUEDA, C., y MOLINOS, M.: "Santuarios y territorios iberos en el Alto Guadalquivir (siglos IV a.n.e.-siglo I d.n.e.)", TORTOSA, T., y CELESTINO, S. (eds.), Debate en torno a la religiosidad protohistórica, Madrid, 2010, 65-81; RUEDA, C.: Territorio, culto e iconografía en los santuarios iberos del Alto Guadalquivir (ss. IV a.n.e.-I d.n.e.), Jaén, 2011; GRAU, I.: "Límite, confín, margen, frontera...Conceptos y nociones en la antigua Iberia", PRADOS, F., GARCÍA, I., y BERNARD, G. (eds.), Confines. El extremo del mundo durante la Antigüedad, Alicante, 2012, 23-48; ADROHER, A.: "El territorio ideológico en el área bastetana", RÍSQUEZ, C., y RUEDA, C. (eds.), Santuarios Iberos: territorio, ritualidad y memoria. Actas del Congreso El santuario de La Cueva de la Lobera de Castellar. 1912-2012, Jaén, 2013, 145-182; GONZÁLEZ REYERO, S., ET AL.: "Procesos de apropiación y memoria en el sureste peninsular durante la segunda Edad del Hierro: Molinicos y la Umbría de Salchite en la construcción de un territorio político", Zephyrus, 73, 2014, 149-170; LÓPEZ MONDÉJAR, L.: "Santuarios y poder ideológico en el sureste ibérico peninsular (siglos IV-III a.C.): paisajes, ceremonias y símbolos", Munibe Antropología-Arkeología, 65, 2014, 157-175.

2. RUEDA: Territorio, culto..., 17-18. 
Desde el punto de vista conceptual es importante porque nos introduce en nuevas formas de analizar las estrategias de plasmación simbólica, más allá del mero objeto, y contribuye a la identificación, en el paisaje, de esquemas mentales definidos, por ejemplo, en el registro iconográfico, permitiendo la comprensión de las cosmovisiones de determinadas sociedades antiguas y de cómo se proyectan en su medio ambiente a través de esquemas mitológicos, a los que se les da forma en el seno del propio paisaje construido. El espacio (también medido en términos territoriales) es, por tanto, una coordenada fundamental de análisis de los sistemas religiosos, pero no cabe duda que debe ir ligado a la variable temporal que, en el contexto de análisis de la religiosidad ibera, posee una fuerte multidimensionalidad. Precisamente, en el contexto de la práctica ritual ibera constatamos cómo el tiempo histórico se nutre y enriquece con el tiempo mítico, ese otro tiempo que nos traslada a ámbitos remotos que contribuyen a revivir el mito y a dar explicación al rito. Los recursos son variados y se materializan a través de la arquitectura sacra, pero también de la propia ofrenda, constatándose en algunos casos procesos de anacronía de la imagen votiva y religiosa, procesos de largo recorrido, perceptibles hasta mediados del siglo I a.n.e. ${ }^{3}$. Por ello, el análisis diacrónico se hace imprescindible, pues nos introduce en aspectos relacionados con la propia transformación de los patrones de asentamiento, del papel de los santuarios o de las modificaciones de los sistemas rituales constados en un mismo espacio de culto con una dilatada historia.

Por otro lado, también desde un punto de vista metodológico, es necesario valorar la trascendencia de la materialidad de las prácticas rituales religiosas insertas en sus paisajes culturales, en sus territorios políticos y sociales, abordando el conjunto desde una práctica interdisciplinar coherente, alejada de las tradicionales perspectivas histórico-culturales. Esto nos fuerza a mirar el registro arqueológico e incluir todas las variables de análisis sin desdeñar la información que aportan aspectos o materiales, tradicionalmente percibidos como secundarios o de importancia menor. De esta manera, para una aproximación al rito y a los mecanismos que rigen la expresión de la estructura litúrgica es necesario profundizar en los modelos y pautas

3. RUEDA, C.: "Las imágenes de los santuarios de Cástulo: los exvotos ibéricos en bronce de Collado de los Jardines (Santa Elena) y Los Altos del Sotillo (Castellar)”, Palaeohispánica, 8, 2008, 55-87 (62); RUIZ, RUEDA y MOLINOS: "Santuarios y territorios...", 69-71; GRAU, I., y RUEDA, C.: "Memoria y tradición en la (re)creación de la identidad ibérica: reviviscencia de mitos y ritos en época tardía (ss. II-I aC)", TORTOSA, T. (ed.), Diálogo e identidades bajo el prisma de las manifestaciones religiosas en el ámbito mediterráneo (s. III a.C. -I d.C.), Madrid, 2014, 101-121; RUEDA, C., y OLMOS, R.: "Las cráteras áticas de la cámara principesca de Piquía (Arjona): los vasos de la memoria de uno de los últimos linajes iberos", RUIZ, A., y MOLINOS, M. (eds.), Jaén, tierra ibera. 40 años de investigación y transferencia, Jaén, 2015, 375-391. 
de comportamiento, en su irregularidad o regularidad, que deja un claro reflejo en el registro arqueológico ${ }^{4}$.

Las liturgias rituales poseen una parte práctica que dota de reglas y códigos de comportamiento $^{5}$, en ocasiones fundamentales para el aprendizaje social. Una parte práctica que se materializa en 'artefactos' que lo definen, como instrumentos activos en la consecución del mismo ${ }^{6}$, o en imágenes que narran, como instantáneas preseleccionadas, el momento elegido ${ }^{7}$. Una de las vías propuestas para profundizar en estos aspectos es la construcción de un método interdisciplinar que englobe e interrelacione técnicas y analíticas aplicadas a registros de naturaleza heterogénea, que comparten un mismo contexto votivo. Un método que requiere de la aplicación de un protocolo de actuación que está dando muy buenos resultados en espacios rituales excavados recientemente y que, a nivel microespacial, contempla la aplicación combinada de análisis tipológicos e iconográficos con analíticas arqueozoológicas, paleoambientales o físico-químicas de determinación de contenidos, entre otras ${ }^{8}$. En conjunto se ofrece una lectura completa que se relaciona con diversos aspectos implicados en la liturgia, no sólo relacionado con el resultado del rito y de la ofrenda, sino incluso con aspectos vinculados a la preparación del instrumental que lo acompaña ${ }^{9}$.

4. GRAU, I., y RUEDA, C.: “Memoria y tradición...”, 119.

5. BELL, C.: Ritual theory, ritual practice, Oxford University Press, Oxford, 1992, 19-21.

6. CHAPA, T.: "Sacrificio y sacerdocio entre los iberos", ESCACENA, J.L., y FERRER, E. (coords.): Entre dios y los hombres: el sacerdocio en la Antigüedad, Sevilla, 2006, 157-180.

7. OLMOS, R.: "La simbolización del espacio sagrado en la iconografía ibérica", DUPRÉ, X., RIBICHINI, S., y VERGER, S. (eds.), Saturnia tellus. Definizioni dello spazio consacrato in ambiente etrusco, itálico, fenicio-punico, ibérico e céltico, Roma, 2008, 251-266.

8. RUEDA: Territorio, culto..., 237-241; SÁNCHEZ, A., PARRAS, D., y RAMOS, N.: "Análisis químico de contenidos en recipientes cerámicos", RUEDA, C.: Territorio, culto e iconografía en los santuarios iberos del Alto Guadalquivir (ss. IV a.n.e.-I d.n.e.), Jaén, 2011, 221-226; RUEDA, C., MOLINOS, M., y RUIZ, A.: "Culto, rito y ofrenda en el santuario periurbano de Las Atalayuelas (Fuerte del Rey)", RUIZ, A., y MOLINOS, M. (eds.), Jaén, tierra ibera. 40 años de investigación y transferencia, Jaén, 2015, 427440; RUIZ, A., ET AL.: "El santuario de la Puerta del Sol", RUIZ, A., y MOLINOS, M. (eds.), Jaén, tierra ibera. 40 años de investigación y transferencia, Jaén, 2015, 93-106; RUIZ, A., ET AL: "El santuario ibero de la Puerta del Sol", RUSSO, A., y GUARNERI, F. (eds.), Santuari Mediterranei tra Oriente e Occidente. Interazioni e contatti culturali, Roma, 2016, 309-319.

9. En relación a este aspecto, la aplicación de análisis físico-químicos (cromatografía de gases-espectrometría de masas -GC-MS- y la cromatografía líquida con ionización química a presión atmosféricaespectrometría de masas -HPLC-APCI-MS-) en el santuario de la Puerta Sur de Puente Tablas ha permitido la identificación de indicadores químicos que muestran la presencia en los recipientes cerámicos de contenidos de naturaleza diversa, como grasa de origen animal, grasa de origen vegetal y cera de abeja. No obstante, ha sido la presencia de azufre nativo la más recurrente en el repertorio cerámico de este santuario, en ocasiones combinada con alguno de los contenidos citados, evidencia que constituye un dato de especial relevancia, por la clara utilidad del uso de este mineral en el ámbito religioso antiguo, vinculado a actos de purificación o a propiedades medicinales. Este es un aspecto al que sólo podemos 
Pero indagar sobre la materialidad del rito no supone negar o invalidar otras categorías de percepción, vinculadas a aspectos inmateriales que son conceptualizados o expresados a través de formas materiales ${ }^{10}$. De algunos de estos aspectos se encargan líneas muy actuales de investigación, como la Archaeology/Archaeologies of the senses definida como una tentativa de concretar cómo se construyen las subjetividades incorporadas a las identidades colectivas y que poseen un fundamento empírico. Una línea de trabajo que, en definitiva, contribuye a articular particularidades que se desarrollan desde disciplinas y técnicas dispares, contribuyendo a una lectura más completa del registro ${ }^{11}$. Se trata de superar el concepto pasivo de la materialidad de los objetos y de profundizar en aspectos que van más allá de las meras representaciones visuales, indagando en los canales de empatía sensorial y emotiva necesarios, por ejemplo, en el desarrollo de la ritualidad y en la construcción de las mitologías, como en el caso de las hierofanías.

\section{ESPACIOS DE CULTO EN CUEVA Y TERRITORIO: APUNTES SOBRE LA Dimensión SIMbólica del PAISAJE}

El paisaje se define como una realidad compleja y polisémica que aúna aspectos de carácter natural con las circunstancias históricas. En él se proyecta lo que se conoce, propiciando que el medio físico cobre sentido y valor, generando lo que se define como 'paisaje familiar' ${ }^{12}$ y seleccionando aquello que sirve para la construcción de las cosmovisiones de una sociedad. En el paisaje se perciben los rasgos impresos por la colectividad, también lo relativo a aspectos simbólicos, ya que la naturaleza se convierte en fuente de metáforas, que enmarcan las creencias y proporcionan explicaciones a las formas de entender el mundo ${ }^{13}$.

En las sociedades iberas los sistemas religiosos están conectados y ligados a la naturaleza. Los territorios iberos poseen una dimensión simbólica clara que se pro-

aproximarnos con la aplicación de técnicas específicas, orientadas a completar la información que ofrece el registro arqueológico; vid. PARRAS, D., ET AL.: "Sulphur, fats and beeswax in the Iberian rites of the sanctuary of the oppidum of Puente Tablas (Jaén, Spain)", Journal of Archaeological Science: Reports, 4, 2015, 510-524.

10. INSOLL, T.: "Ritual and religion in archaeological perspective", INSOLL, T. (ed.), The Oxford Handbook of the Archaeology of Ritual and Religion, Oxford, 2011, 1-5 (2).

11. HAMILAKIS, Y.: “Archaeology of the Senses", INSOLL, T. (ed.), The Oxford Handbook of the Archaeology of Ritual and Religion, Oxford, 2011, 208-225 (209-211); ID.: Arqueología y los sentidos. Experiencia, memoria y afecto, Madrid, 2015.

12. LÓPEZ-BERTRÁN, M.: "Practical movements: kinetic rituals in the Ancient Western Mediterranean", Journal of Mediterranean Archaeology, 24, 1, 2011, 85-109 (92).

13. URQUIJO, P. S.: "El paisaje en su connotación ritual. Un caso en la Huasteca potosina, México", Geotrópico, 2, 2010, 2-15. 
yecta en hitos del paisaje, que se conceptualizan e incluso participan en las narraciones mitológicas ${ }^{14}$. En concreto veremos cómo la cueva, como hito natural destacado, contribuye y se integra en esas historias míticas que se suceden en un espacio y en un tiempo, extraordinarios. El acceso a la naturaleza, como materialización de esta dimensión sagrada, se rige por códigos religiosos que se potencian cuando se transita a los límites del territorio, a esos espacios liminales que se rigen por normas concretas, tan alejadas de lo cotidiano ${ }^{15}$. Las peregrinaciones a los espacios y pasajes sagrados aseguran la comunicación con lo divino y convierte a estos lugares, en palabras de Silvia Alfayé, en 'territorios de gracia'16. El peregrinaje, en sus diversas variantes, no deja de ser una forma más de apropiación del paisaje sagrado como espacio cargado de significados culturales de tradición ${ }^{17}$, que forman parte de la memoria de la comunidad (también de la memoria individual) y que se refuerza a través de comportamientos rituales cíclicos y de pautas de repetición.

El paisaje, por tanto, como construcción histórica posee una vertiente simbólica demarcada, como proyección de la cosmovisión de una sociedad. Una dimensión que no excluye otras funcionalidades, sino que conlleva un proceso de significación de una zona dentro de un código de lectura de carácter simbólico-ideológico ${ }^{18}$. Las cosmovisiones en la religiosidad ibera definen formas de narración propias que son convertidas en memoria, fosilizadas en imágenes, pero también en el territorio. Una mirada a la iconografía ibera nos ayuda a comprender los ámbitos definidos para el modelo de vida de estas sociedades protohistóricas y cómo este esquema, que articula relaciones de índole diversa, se proyecta en los territorios, pues la imagen ibera participa de esos ámbitos de relación ${ }^{19}$. Así el oppidum se convierte en el centro de las relaciones de vecindad, aquellas que se muestran y desarrollan en el espacio político controlado, que se define como complementariedad al espacio rural, el que rige las relaciones con la naturaleza. De ella se derivan al menos dos acepciones, dependien-

14. RUIZ, RUEDA y MOLINOS: “Santuarios y territorios...", 65-81; GRAU, I., y AMORÓS, I.: "La delimitación simbólica de los espacios territoriales ibéricos: el culto en el confín y las cuevas-santuario", RÍSQUEZ, C., y RUEDA, C. (eds.), Santuarios Iberos: territorio, ritualidad y memoria. Actas del Congreso El santuario de La Cueva de la Lobera de Castellar. 1912-2012, Jaén, 2013, 183-212; GONZÁLEZ REYERO ET AL.: "Procesos de apropiación...," 149-170.

15. BRADLEY, R.: An Archaeology of Natural Places, London-New York, 2000.

16. ALFAYÉ, S.: "Hacia el lugar de los dioses: aproximación a la peregrinación religiosa en la Hispania indoeuropea”, MARCO, F., PINA, F., y REMESAL, J. (eds.), Viajeros, peregrinos y aventureros en el mundo antiguo, Barcelona, 2010, 177-218 (179).

17. LÓPEZ-BERTRÁN: "Practical movements...”, 91.

18. SANTOS, M., PARCERO, C., y CRIADO, F.: "De la arqueología simbólica del paisaje a la arqueología de los paisajes sagrados”, Trabajos de Prehistoria, 54, 2, 1997, 61-80 (62).

19. OLMOS: “La simbolización del espacio..., 251-266. 
do del grado de transformación o apropiación de la misma. De un lado, se presenta el espacio natural controlado (ager) y, frente a éste, el ámbito de la naturaleza salvaje (saltus), donde lo físico y lo sobrenatural se entremezclan, caracterizado además por constituirse como un ámbito de vegetación salvaje, no controlada que concreta el límite del espacio de residencia ${ }^{20}$. A esta dualidad hay que sumar un tercer ámbito, el espacio mítico, que define las relaciones con los antepasados y con las divinidades, que se expresa en las construcciones simbólicas y en las fórmulas de demostración política ${ }^{21}$. Todas estas dimensiones se complementan entre sí.

En la construcción de este esquema ideal, síntesis de concepciones generales de cómo se concibe el mundo, se define claramente el espacio de lo liminal, aquel que se encuentra alejado del oppidum y en el que se encarna lo opuesto a lo cotidiano. A este ámbito se asocian, en muchas ocasiones (aunque con matizaciones, como se verá a continuación), las cuevas como espacios sacros de referencia. La cueva, en este contexto, adquiere la propiedad de condesar símbolos que ayudan a crear otros mundos diferentes, pues una de las propiedades fundamentales de estos espacios liminales es la de fijar aquello que debe ser visto en 'ese otro mundo' en contradicción con lo construido socialmente como normal o cotidiano ${ }^{22}$, contribuyendo a acentuar asimismo los estadios liminales de la persona ${ }^{23}$.

Bajo estos planteamientos, el análisis de los espacios de culto en cueva requiere de una perspectiva amplia, que integre su localización y el papel que juega en el contexto del territorio y su vinculación a espacios urbanos. Por ello creemos básico integrar el conocimiento del territorio político en el análisis de estos santuarios, por lo que nuestra aportación a este trabajo se va a centrar en los espacios de culto del Alto Guadalquivir, aunque contaremos con referencias de contraste próximas que se sustentan en análisis territoriales.

En los territorios iberos del Alto Guadalquivir contamos con diferentes tipos de santuarios en los que la cueva o el abrigo se convierten en un hito funcional, pero también simbólico, que define el espacio de culto y que delimita la práctica ritual. No obstante, antes de abordar estas cuestiones desde casuísticas concretas, cabría hacer algunas matizaciones iniciales. Una de ellas tiene que ver con la extensión del término cueva-santuario que, más allá de fijarse como una denominación genérica,

20. RUIZ, A., y SÁNCHEZ, A.: "La cultura de los espacios y los animales entre los príncipes del sur", TORTOSA, T., y SANTOS, J.A. (eds.), Arqueología e iconografía. Indagar en las imágenes, Roma 2003, 137-154 (137-138); GRAU: “Límite, confín..., 33-34.

21. RUEDA, C.: "La religiosidad en las sociedades iberas de los siglos IV-III a.C.", Arqueología \& Historia, 1, 2015, 4-9 (4-5).

22. GARWOOD, P.: "Rites of passage", INSOLL, T. (ed.), The Oxford Handbook of the Archaeology of Ritual and Religion, Oxford, 2011, 261-283 (275).

23. ALFAYÉ, S., y RODRÍGUEZ-CORRAL, J.: "Espacios liminales y prácticas rituales en el noroeste peninsular”, Palaeohispánica, 9, 2009, 107-111 (107). 
ha potenciado que espacios de culto de territorios distintos y con rasgos diferenciables sean analizados bajo una misma categoría conceptual, que ha tendido a cierta homogeneización de realidades religiosas diferentes ${ }^{24}$. En un reciente análisis, Grau y Amorós acentuaban cómo estas circunstancias han "enfatizado lo que estos espacios sacros tienen en común y ha obviado las particularidades", a pesar de que la revisión que hacen estos autores del territorio contestano pone de manifiesto cierta variabilidad funcional ${ }^{25}$. Un diagnóstico parecido es del que partimos en el estudio de los espacios de culto en cueva o 'con cueva' en el Alto Guadalquivir. En nuestro caso observamos cómo no sólo la función y la ritualidad manifiesta es diferente en los santuarios que pertenecen a territorios distintos, sino que el papel de la cueva es, asimismo, distinto. Esto nos lleva a una segunda apreciación sobre la función de este hito topográfico y natural en el contexto ritual, ya que vamos a encontrar algún ejemplo en el que la cueva es un elemento meramente simbólico que contribuye a enriquecer la lectura y el discurso mítico del propio santuario. Tres son los ámbitos territoriales que nos servirán de guía para analizar aspectos relacionados con el culto en cuevas, con las motivaciones del rito y los canales de subsanación de los miedos y con las narraciones míticas vinculadas a la divinidad femenina ibera. A ellos pertenecen santuarios de tipología diferente, lo que permite abordar experiencias y expresiones religiosas igualmente diversas.

\section{SANTUARios territoriales de Collado de los JARdines (SANTA Elena, Jaén) y de la Cueva de la lobera (Castellar, Jaén)}

Pertenecen al territorio de Cástulo, localizándose en los confines, como límites físicos y simbólicos de un amplísimo territorio que evoluciona de un modelo de pagus a un esquema que puede definirse como suprarregional ${ }^{26}$. Desde mediados del siglo IV a.n.e. y en el desarrollo del siglo III a.n.e. se convierten en grandes centros de culto, espacios donde se sancionan prácticas fundamentales para las comunidades que forman parte de esta gran unidad política, entre las que adquieren un papel importante los ritos de paso, pero también otro tipo de ritualidades vinculadas con la curación y a la protección. En la estructura ritual de estos santuarios todas estas ritualidades contribuyen a reforzar las prácticas de agregación y de identificación social que po-

24. GONZÁLEZ-ALCALDE, J.: "Estudio historiográfico, catálogo e interpretación de las cuevas-refugio y cuevas-santuario de época ibérica en Alicante”, Recerques del Museu d’Alcoi, 11-12, 2002-2003, 57-84.

25. GRAU y AMORÓS: “La delimitación simbólica...”, 187.

26. RUIZ ET AL.: "El modelo político...", 11-22; RUIZ, A., ET AL.: "El factor ibero en la Batalla de Baecula: los efectos colaterales de la guerra", Cuadernos de Prehistoria y Arqueología de la Universidad de Granada, 23, 2013, 199-225. 
seen una dimensión claramente colectiva ${ }^{27}$. La frecuentación de estos espacios de culto hasta finales del siglo III a.n.e. debió ser importante, aspecto que queda reflejado en sus contextos votivos, los cuales se convierten en imponentes tesauros contenedores de varios miles de ofrendas, entre las que destacan los exvotos en bronce como la principal categoría votiva y soporte iconográfico de carácter identitario ${ }^{28}$. (Fig. 1)

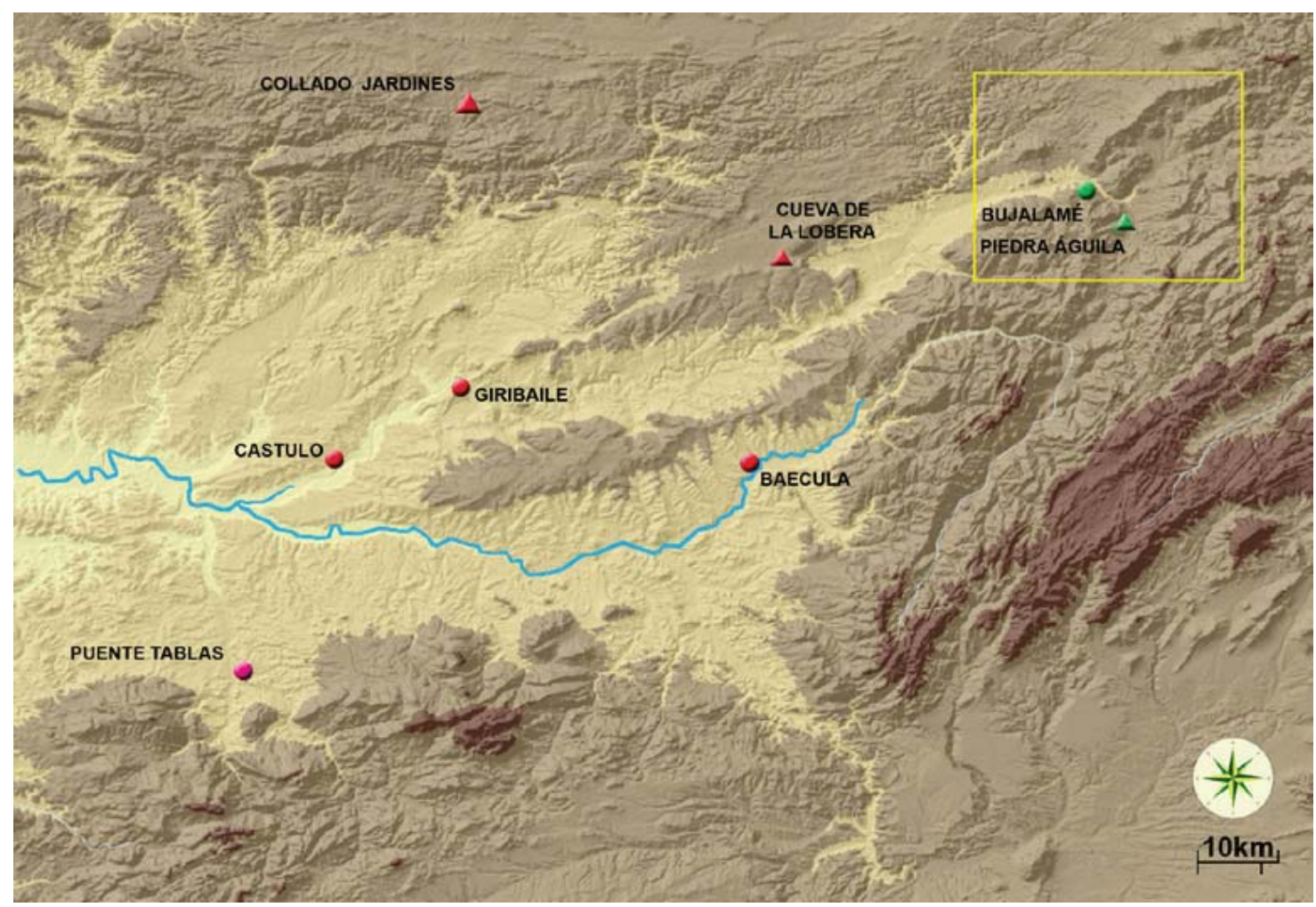

FIG. 1

Son espacios de culto de carácter supra-regional a los que se peregrinaría en fechas concretas del calendario ceremonial, y en los que los equinoccios parecen jugar un papel regulador de las pautas anuales o estacionales (al menos para el santuario de Castellar) acompañados por fenómenos astrológicos vinculados al ocaso ${ }^{29}$. La locali-

27. RUEDA: Territorio, culto..., 153-159.

28. RUEDA: "Las imágenes de los santuarios...", 55-87.

29. ESTEBAN, C., RÍSQUEZ, C., y RUEDA, C.: "Una hierofanía en el santuario ibérico de Castellar (Jaén)”, Archivo Español de Arqueología, 87, 2014, 91-107; ESTEBAN, C., RÍSQUEZ, C., y RUEDA, C.: "An evanescent vision of the divinity. The equinoctial sun at the iberian sanctuary of Castellar", International Journal Mediterranean Archaeology and Archaeometry, 14, 3, 2014, 99-106. 
zación de los santuarios, muy distantes de los núcleos habitados, fuerza a emprender un viaje que supera la escala regional, que debió tener en algunos casos claras connotaciones iniciáticas y de superación, clave en la vida religiosa de estas comunidades.

Desde el punto de vista estructural ambos espacios de culto comparten un esquema similar en el que el abrigo, en Collado, y la cueva, en Castellar, se convierten en los hitos topográficos, simbólicos y funcionales principales, en torno a los que se organizan las distintas terrazas y espacios de celebración ritual. Esto asociado a fuentes naturales y manantiales que debieron integrarse de manera activa en el rito. La cueva, en el caso de Castellar, adquiere un papel ritual clave, relacionado con la narración mítica de la divinidad tutelar, aspecto éste que será tratado de forma detallada más adelante.

\section{Santuario extraurbano de la Piedra del Águila (Orcera, Jaén)}

Se trata de un espacio de culto perteneciente al territorio del oppidum de Bujalamé (Puerta de Segura, Jaén), recientemente excavado y aún inédito. Fechado en el siglo III a.n.e., este espacio de culto debe entenderse con en el desarrollo de la colonización que lleva a cabo Bujalamé hacia el valle enmarcado por los ríos Guadalimar y Trujala, un área de influencia inmediata que se caracteriza por su alta potencialidad agrícola. Para ello este oppidum, que se ubica en un punto privilegiado de control del acceso a la sierra a través del valle del Guadalimar, articula un sistema poblacional en el que se sitúa como cabecera capital y en el que se apoya de oppida de pequeñas dimensiones, como el Cerro de la Virgen o Cerro Cabeza Grande, y de otros asentamientos menores como Cerro Castellones o Cerro del Cura ${ }^{30}$. (Fig. 2)

En este esquema, este santuario de carácter local se ubica en el extremo sur del territorio, sancionando la proyección de este oppidum hacia esta zona, convirtiéndose en un hito topográfico perceptible y de donde se controla toda la amplitud del valle apropiado. Asimismo demarca su área de estrechamiento y límite del mismo, punto que empieza a delimitarse por la presencia de cotas elevadas que acaban cerrándolo hacia la zona de Segura de la Sierra, siguiendo y controlando así el curso del río Trujala. Se convierte en un testigo para la sacralización de los límites del control de este territorio, coincidiendo con una frontera natural/física, un esquema que es perceptible en otras áreas iberas del sureste ${ }^{31}$.

30. ALCALDE, J., ET AL.: "Integración de las investigaciones arqueológicas del alto valle del Guadalimar,en la Sierra de Segura, en el ámbito del Alto Guadalquivir. El oppidum de Bujalamé (Puerta de Segura, Jaén)", Caesaraugusta, 78, 2007, 321-330 (327-328).

31. GRAU y AMORÓS: “La delimitación simbólica...”, 183-212; GONZÁLEZ REYERO ET AL.: “Procesos de apropiación...", 149-170. 
Desde punto de vista cultual, recientes excavaciones arqueológicas han permitido documentar un sistema de culto muy pautado basado en comportamientos rituales que se repiten y se suceden, en los que intervienen las ofrendas de alimentos, que son quemados in situ y posteriormente ofertadas en depósitos subterráneos elaborados para tal fin. Es importante señalar que la ofrenda es fundamentalmente de carácter vegetal, principalmente cereales y leguminosas, constatando cómo la presencia de ofrenda animal, en un cómputo general, posee poca representatividad. Todos los rituales documentados se realizan al interior de la cueva, convirtiéndose ésta en el lugar de rito y contenedor de la memoria de las celebraciones rituales.

\section{Santuario urbano de la Puerta del Sol del oppidum de Puente TABLAS (JAÉN).}

Nuestro tercer modelo es un santuario urbano, localizado en la puerta sur de este oppidum giennense, que canaliza el culto de esta ciudad desde finales del siglo $\mathrm{V}$ a.n.e. hasta finales del IV a.n.e., aunque a mitad de este siglo sufre una fuerte reestructuración. Lejos de constituirse como un modelo básico y reiterado, se trata de un espacio excepcional en el que confluyen multitud de aspectos (espaciales, simbólicos, materiales, funcionales, etc.) que nos sitúan ante un santuario organizado en función de una compleja mitología de la divinidad femenina, sobre la que se sustentan un conjunto de ritos que definen el culto aristocrático del linaje ibero de esta ciudad ${ }^{32}$. (Fig. 3)

La monumentalidad de este espacio de culto ${ }^{33}$ se percibe en su propia articulación en tres terrazas artificiales que salvan el desnivel natural de la zona y contribuyen a potenciar lo singular del espacio sagrado. Su ubicación, junto a una de las puertas de la ciudad, debe explicarse desde argumentos diferentes, pero complementarios. De esta forma, 'la puerta del Sol' no es la entrada comercial de la ciudad, más bien es una puerta representativa y simbólica que forma parte del complejo religioso, pues al final de su corredor y delante del edificio religioso, se halló una escultura antropoide que representa a la divinidad.

El edificio del santuario, de más $300 \mathrm{~m}^{2}$ de planta, se organiza en terrazas ascendientes, que articulan los circuitos rituales:

- Primera terraza: da acceso al santuario a través de una puerta lateral que abre a un patio, en cuyo lateral destaca la presencia de una gran piedra en forma de piel de toro. Su ubicación no es inocente ni aleatoria, pues marca el

32. RUIZ ET AL.: "El santuario de la Puerta...", 93-106; RUIZ ET AL.: "El santuario ibero...", 309-319.

33. Para una descripción detallada de este santuario, vid. RUIZ ET AL.: "El santuario de la Puerta...", 93-106; RUIZ ET AL.: "El santuario ibero...", 309-319. 


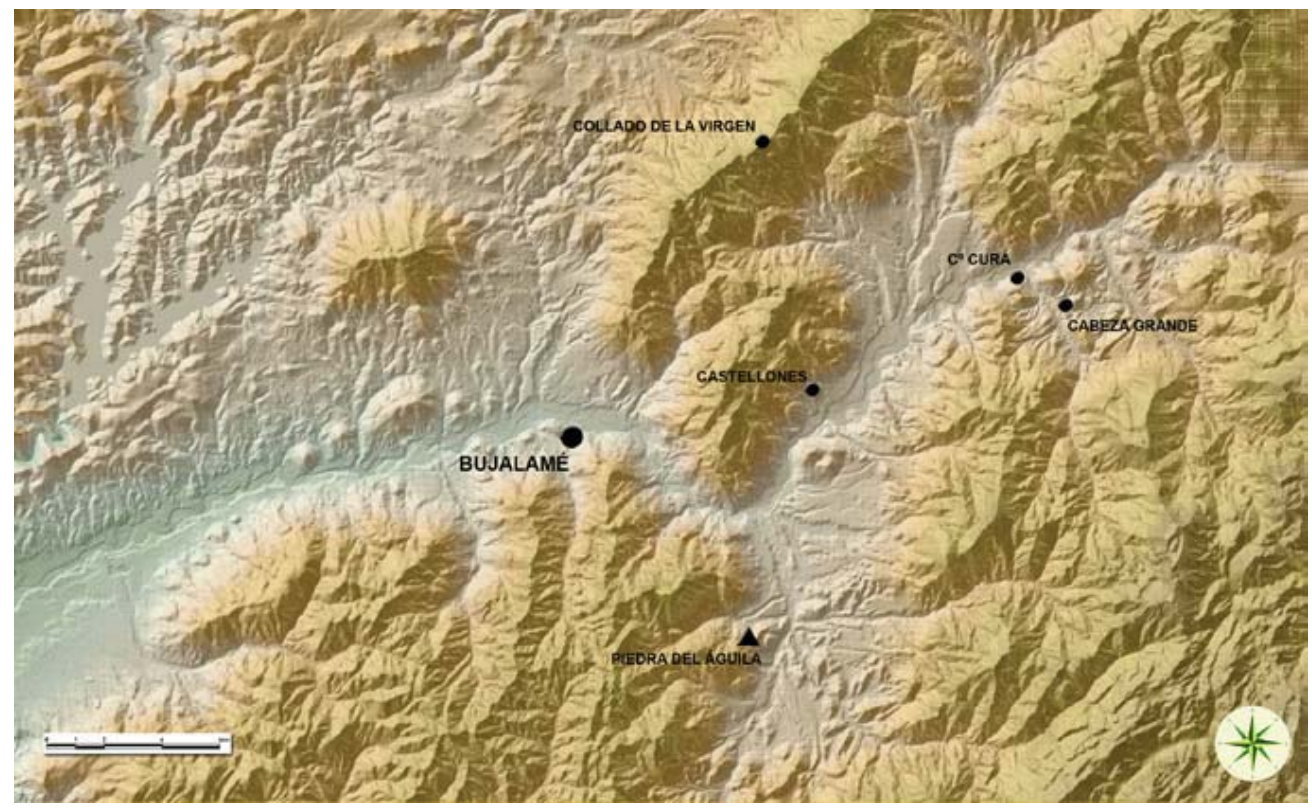

FIG. 2

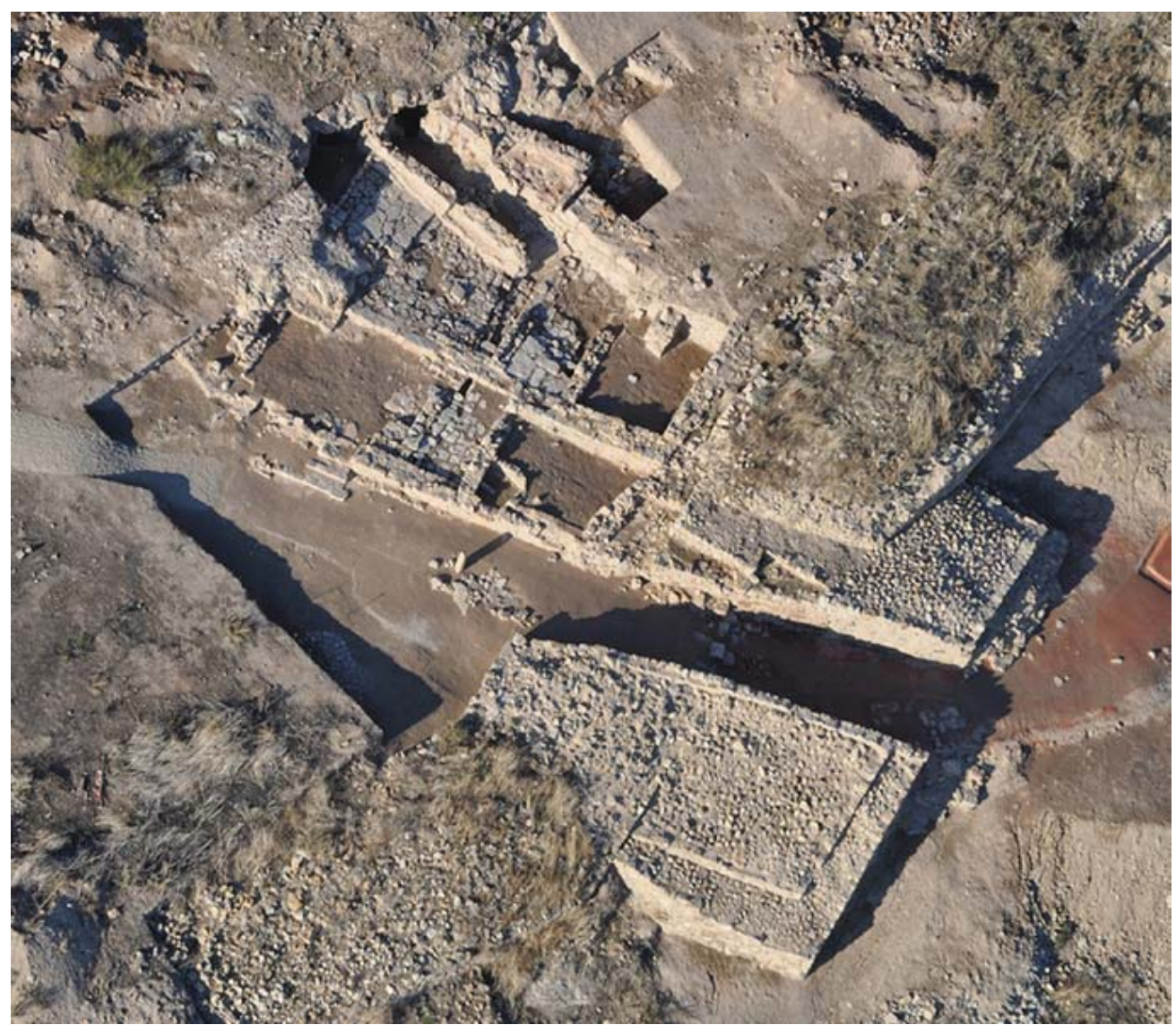

FIG. 3 
acceso a un área importante del espacio de culto, la cella, en la que se integra la capilla en la que la estela estaría localizada parte del año.

- Segunda terraza: la reservada a la celebración de los ritos. Esta terraza se divide en distintos espacios funcionales. De un lado, al este, se documenta una estancia cuadrangular, de dos plantas, que se configura como un espacio a modo de torre, cuya función específica en el rito es difícil de establecer, pero que debió tener un papel importante, tal y como se intuye por la presencia en su entrada de diferentes bothroi con restos de sacrificio de corderos. Frente a la torre se dispone un ámbito abierto y semi-cubierto: un patio que se define como un área principal para el desarrollo de distintos rituales. Destaca en su extremo oeste la presencia de una plataforma enlosada, en la que se disponen (de manera regular) tres pequeños altares de libación que coindicen con tres de las cuatro pequeñas cuevas a las que se abre el complejo. El simbolismo espacial viene demarcado por la presencia de estos elementos naturales que en el santuario de Puente Tablas se asocian a lo sagrado en dos vertientes: de un lado, la de la práctica ritual (vinculado a estas tres cuevas) y, de otro, la relacionada con la explicación sagrada del mito de la divinidad tutelar de la ciudad (asociada a una cuarta cueva, separada del complejo anterior). Las cuevas en este caso intervienen como símbolos sobre los que se construye la mitología que da sentido al rito. Se entrará en ello más adelante.

- Tercera terraza: la más alta, se reserva como un espacio de servicios, en la que se han documentado restos de hogares que pueden relacionarse con la preparación de los productos implicados en el ritual. Asimismo, en esta área se ha documentado un aljibe que distribuye el agua desde una cota elevada al resto del edificio. De hecho, el agua se constituye en otro elemento simbólico y funcional clave en este espacio de culto, pues se integra en una escenografía litúrgica en la que las prácticas de libación, complementarias a las de sacrificio, adquirieron un papel significativo, fundamentalmente en el área de la plataforma de las tres cuevas.

Los ritos de paso o iniciación, tan importantes en la religiosidad ibera ${ }^{34}$, adquirirían un papel importante en el culto de este santuario. Posiblemente como parte de una estructura litúrgica más amplia que incluyera otros tipos de prácticas, como las relacionadas con la fertilidad, aspecto, que lejos de ser contradictorio, es habitual en

34. RUEDA, C.: "Ritos de paso de edad y ritos nupciales en la religiosidad ibera: algunos casos de estudio", RÍSQUEZ, C., y RUEDA, C. (eds.), Santuarios Iberos: territorio, ritualidad y memoria. Actas del Congreso El santuario de La Cueva de la Lobera de Castellar. 1912-2012, Jaén, 2013, 341-383. 
el ámbito litúrgico ibero. Se constituye por tanto como un santuario de carácter local, que contribuye a reforzar el culto aristocrático a partir de mecanismos de satisfacción y autoafirmación que tienen en las narraciones míticas de la divinidad femenina un recurso esencial.

Como se ha mostrado, existen evidentes diferencias en la naturaleza y función, a distintas escalas, de estos espacios de culto. Nos fijaremos, a expensas de desarrollar otros aspectos más adelante, en algunas propiedades relacionadas con la expresión religiosa en el paisaje y con los canales de subsanación y satisfacción, que hacen referencia a la movilidad, a la escala de participación y a la motivación ritual.

Movilidad ritual: como se ha expuesto, el alcance de estos santuarios nos sitúa ante escalas territoriales y paisajísticas diferentes, ya que implican desplazamientos también a distintas escalas, lo cual es extensible a otros territorios del área ibera ${ }^{35}$. En el caso de los santuarios de Cástulo, comprobamos una movilidad más amplia, que requiere de varias jornadas de viaje, puesto que nos movemos en distancias superiores a los $40 \mathrm{~km}$. Este aspecto requiere del apoyo de infraestructuras y de la existencia de una articulación a nivel supra-regional para la consecución de estas peregrinaciones que, muy probablemente, llevaban implícita la ritualidad del movimiento ${ }^{36}$. Diferente caso es el de la cueva de la Piedra del Águila, localizada a unos $10 \mathrm{~km}$. de la capitalidad del territorio y a poco más de $11 \mathrm{~km}$ del asentamiento más alejado, en ambos casos siguiendo los cursos fluviales del Guadalimar y del Trujala. Los movimientos rituales, vinculados al traslado al santuario territorial, se pueden llevar a cabo en un día de viaje, un peregrinaje por el valle que posee como referencia visual la cueva. El tercer ejemplo o modelo planteado, el santuario de la puerta sur de Puente Tablas, nos permite abordar otro tipo de movilidad, a escala microespacial, que se restringe al oppidum. No es un caso exclusivo, ya que la cueva interviene y se relaciona con cultos urbanos en otro oppidum oretano, como es Giribaile (Vilches, Jaén $)^{37}$, en ese caso a extramuros del oppidum, como simbología del espacio liminal traído a la ciudad que pudo conllevar, asimismo, la atracción de la población rural del territorio colindante.

Escala de participación: una variable importante a introducir es la densidad de la movilidad, aspecto que nos habla de la implicación poblacional en el culto territorial y que nos ofrece una perspectiva sobre el movimiento ritual de personas. Bien es cierto que es una variable de aproximación muy compleja, ya que en la mayor

35. GRAU: La organización del territorio....

36. LÓPEZ-BERTRÁN: "Practical movements..., 91-92.

37. GUTIÉRREZ L. M.: Guía arqueológica de Giribaile, Jaén, 2011. 
parte de los casos carecemos de evidencias arqueológicas del transcurso y volumen de las peregrinaciones. Es, por tanto, el contexto ritual, el lugar de destino, el que nos ofrece algunos datos de referencia con los que trabajar. Para ello, los santuarios territoriales de Cástulo se convierten en referencia experimental. Abordando un cómputo aproximado de sus contextos votivos, que ya hemos indicado que superan los varios miles de ofrendas, y concretamente aproximándonos a la imagen votiva principal (de carácter individual) y signo identitario del culto territorial en estos santuarios, como son los exvotos de bronce, que en una cuantificación mínima supera los 6000 ejemplares entre ambos santuarios ${ }^{38}$, podemos afirmar la amplísima participación en el culto en estos santuarios, lo que comporta una participación igualmente considerable. Más complicado, no obstante, es analizar la escala de participación en espacios de culto de los que quedan huellas de rituales de carácter colectivo ${ }^{39}$, donde la individualidad es menos perceptible, como es el caso de la Piedra del Águila.

Motivación ritual: tampoco la naturaleza cultual y ritual de todos estos espacios de culto nos sitúa ante situaciones o modelos homogéneos. En el análisis de las motivaciones sobre las que se sustenta la ritualidad ibera hay que tener en cuenta aspectos de orden cronológico y de la propia evolución de los cultos que van unidas a las transformaciones internas del sistema político aristocrático. De esta forma, el santuario de Puente Tablas (finales del siglo V a.n.e. - mitad del IV a.n.e.) define el momento de un culto eminentemente aristocrático, controlado y de acceso restringido, que se sustenta en prácticas de iniciación que refuerzan las estrategias de progresión dentro del sistema aristocrático. Hacia mediados del siglo IV a.n.e. constatamos, a partir del paradigma generado por Collado de Los Jardines y la Cueva de la Lobera, los santuarios situados en el confín del territorio se definen como espacios de cohesión, básicos para el mantenimiento de una estructura política jerarquizada suprarregional, que se sirve de estrategias religiosas de filiación identitaria. Diferentes son las motivaciones suscitadas desde el culto eminentemente agrícola, como el que se documenta en el santuario de la Piedra del Águila, que conlleva una estacionalidad implícita en la práctica, así la reiteración de sistemas de comportamiento ritual que quedan fosilizados al interior de la cueva.

38. NICOLINI, G.: Les Bronzes Figurés des Sanctuaires Ibériques, Paris, 1969, 35.

39. PRADOS, L.: "La participación de la comunidad, las unidades domésticas y los individuos en los rituales de los santuarios de la cultura ibérica", TORTOSA, T. (ed.), Diálogo de identidades. Bajo el prisma de las manifestaciones religiosas en el ámbito mediterráneo (s. III a.C. - s. I d.C.), Madrid, 2014, 135-146. 


\section{LA ESCENOGRAFÍA: MONUMENTALIZACIÓN, ACCESO E ITINERARIOS RITUALES}

Está ampliamente analizado cómo las cuevas, en distintos esquemas religiosos antiguos, se conciben como puntos de conexión de diferentes planos de la realidad ${ }^{40}$. A ellas se les atribuyen cualidades especiales que se potencian y adaptan en el desarrollo del ritual. También en ellas recae una gran carga simbólica, en relación con la manifestación de lo sagrado, demarcándose en algunos casos como lugares centrales, a los que se les atribuye un significado cosmológico $^{41}$, en ocasiones reforzado por la presencia de ocupaciones anteriores, que pudieron utilizarse como herramientas de ritualización de la memoria del paisaje y de las prácticas rituales ${ }^{42}$.

En los espacios de culto analizados, la escenografía ritual se sustenta en gran parte en estos hitos naturales, adoptando soluciones heterogéneas en relación a la circulación ritual, que se asocian al tipo y función del santuario en cuestión ${ }^{43}$. La cueva, como lugar central, en ocasiones es potenciada por la construcción de terrazas y accesos que demarcan los recorridos, su observación desde cotas bajas y su aproximación en un recurso ascendente hacia el lugar donde mora y habita la divinidad, configurando un escenario jerarquizado. El santuario de Collado de los Jardines es un claro ejemplo de la relación del espacio de culto con aspectos simbólicos del marco natural, de la naturaleza salvaje, todo ello utilizado como monumentalización del discurso religioso asumido por esta comunidad ${ }^{44}$ (Fig. 4). Un proceso similar es documentado, de manera más precisa, en el análogo santuario de La Cueva de la Lobera. En este caso se han podido constatar arqueológicamente los sistemas de aterrazamiento que dan organicidad, definen y delimitan el acceso a la cueva principal, centro neurálgico del culto. Uno de los recorridos principales potencia el ascenso desde las cotas bajas del valle, serpenteando a través de la ladera, lo que genera una percepción frontal y de amplitud visual. Lejos de restringirse a una solución práctica, este recorrido contribuye a un ascenso controlado y reglado, medido en términos escenográficos, a un espacio vital del rito en este santuario, hasta el punto de que el último tramo el

40. BRADLEY: An Archaeology...; ALFAYÉ: “Hacia el lugar...”, 177-218; LÓPEZ-BERTRÁN: "Practical movements..., 85-109.

41. LÓPEZ-BERTRÁN: “Practical movements...”, 92.

42. ALFAYÉ, S.: Imagen y ritual en la Céltica peninsular, A Coruña, 2011, 162-163.

43. CONELLY, J.: "Ritual movement in sacred space: towards and archaeology of performance", CHANIOTIS, A. (ed.), Ritual dynamics in the Ancient Mediterranean. Agency, emotion, gender, representation, Stuttgart, 2011, 313-346 (315).

44. RUEDA: Territorio, culto..., 83-85. 


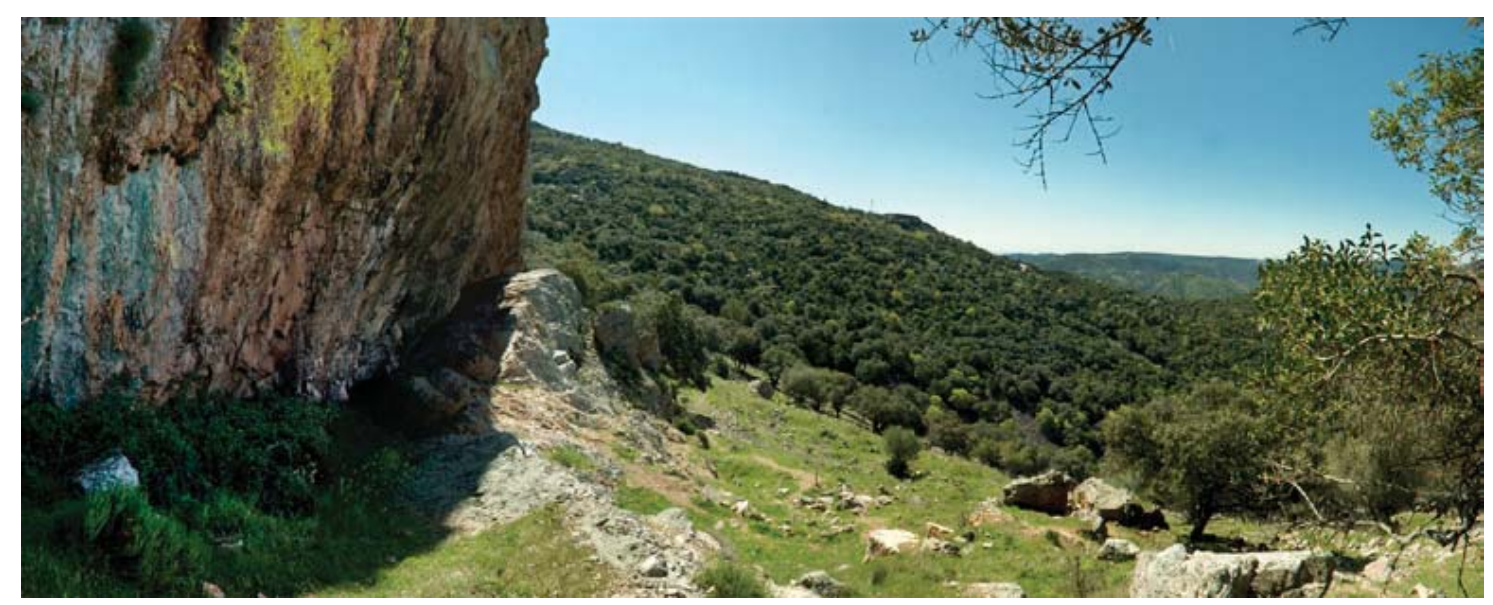

FIG. 4

camino se estrecha, convirtiéndose en un acceso en escalones excavados en la roca, que fuerza y limita al acceso individual ${ }^{45}$. (Fig. 5)

En las variables monumentales o escenográficas de los espacios de culto en cueva hay que introducir otras que tienen que ver con la propia morfología exterior de la cueva que, en algunos casos conocidos, aluden a rasgos 'que sugieren' aspectos fisionómicos o antrópicos. El santuario de la Umbría de Salchite, también llamado de La Nariz, en Moratalla, es un ejemplo muy alusivo ${ }^{46}$, pero también La Cueva de la Lobera, que adquiere rasgos faciales en su cavidad principal, aspecto simbólico que no parece ser fruto de la casualidad, dado que la propia entrada se encuentra retocada y orientada frontalmente respecto del camino que conduce a la misma. Esta cavidad con rasgos faciales humanos ocupa, por tanto, un lugar medular dentro de un complejo sagrado salpicado por otras cuevas y abrigos menores. Funcionalmente es muy interesante la diferenciación en dos áreas (Fig. 6):

- $\quad$ el área oeste que se configura como un abrigo de unos $9 \mathrm{~m}$ de anchura, que da paso a una pequeña cueva, sobre-elevada, a la que se accede por un sistema de escalones muy toscos, recortados en la roca que debió tener un papel determinante de depósito de ofrendas, junto a la zona más exterior, lugar

45. NICOLINI, G., ET AL.: El santuario ibérico de Castellar, Jaén. Intervenciones arqueológicas 19661991, Sevilla, 2004, 149-153; RÍSQUEZ, C., RUEDA, C., y GARCÍA, M. A.: Un Plan Director para el santuario ibero de la Cueva de la Lobera (Castellar, Jaén), Jaén, 2013, 40-45.

46. OCHARÁN, J. A.: "Aproximación al estudio de los santuarios rupestres ibéricos de la región de Murcia: La Naríz (Moratalla, Murcia)", RÍSQUEZ, C., y RUEDA, C. (eds.), Santuarios Iberos: territorio, ritualidad y memoria. Actas del Congreso El santuario de La Cueva de la Lobera de Castellar. 1912-2012, Jaén, 2013, 289-303; GONZÁLEZ REYERO ET AL.: “Procesos de apropiación...”, 149-170. 
donde, según las noticias antiguas, se situaba un gran depósito de ofrendas $^{47}$. Un rasgo a destacar es la presencia, en un lateral, de un manantial de agua, que aún es perceptible, al que se asocia una pequeña balsa o pozo excavado en la roca de manera artificial.

- el área este lo ocupa la cueva principal y más grande del conjunto (con unas dimensiones aproximadas de $10 \mathrm{~m}$ ), que destaca, tal y como se ha indicado, por su fisionomía exterior. En el centro de la misma se aprecia un trabajo tallado en la roca a modo de mesa, mientras que al fondo se observa un escalón que realza el nivel del suelo original unos $80 \mathrm{~cm}^{48}$. Al oeste se aprecia un estrechamiento de la misma, con orientación ascendente, que desemboca en un pequeño orificio, que es el lugar donde se proyecta el sol en el ocaso del equinoccio, cuando el rayo de luz atraviesa un ventanuco tallado artificialmente en la cara oeste de la cavidad, produciendo un fenómeno interpretado como una hierofanía solar ${ }^{49}$. La función principal de esta cueva, como veremos, se asocia a las narraciones míticas de la divinidad, en una concepción de la cueva como templo natural, espacio de hábitat y surgimiento cíclico de la divinidad desde las entrañas de la tierra.

Frente a este esquema simbólico y funcional contraponemos el modelo documentado en la Piedra del Águila (Fig. 7). En este caso nos encontramos con un espacio de difícil acceso, que requiere una inversión de tiempo y esfuerzo debido a su abrupta topografía. El acceso más viable a la cueva se desarrolla desde la ladera este, bordeando el farallón rocoso hasta llegar a una apertura en la que se perciben algunas terrazas artificiales que reorganizan la ascensión hasta la mima boca de la cueva. En este punto, el camino se redefine y estrecha, se encajona, generando un camino escalonado, de pendiente acentuada, al que solo se puede acceder individualmente. Este recurso de forzar la entrada individual, habitual en muchos de estos espacios, se prolonga hasta la misma entrada de la cueva potenciando un acceso reglado, que se realiza en descenso, un recurso simbólico que se integraba en el rito, pues se entra a un espacio oscuro, que potencia la privación del sentido de la vista, como ámbito multisensorial en el que se potencian determinados sentidos frente a otros ${ }^{50}$. El hecho de descender pudo funcionar también como un recurso simbólico relacionado con la bajada al inframundo, potenciado por la ritualidad documentada en este santuario, en la que juegan un papel importante los depósitos subterráneos.

47. LANTIER, R.: El Santuario ibérico de Castellar de Santisteban, Madrid, 1917.

48. NICOLINI ET AL.: El santuario ibérico de Castellar..., 149.

49. ESTEBAN, RÍSQUEZ y RUEDA: "Una hierofanía...”, 91-107; EAD.: “An evanescent vision...”, 99-106.

50. ALFAYÉ: "Hacia el lugar...", 177-218. 


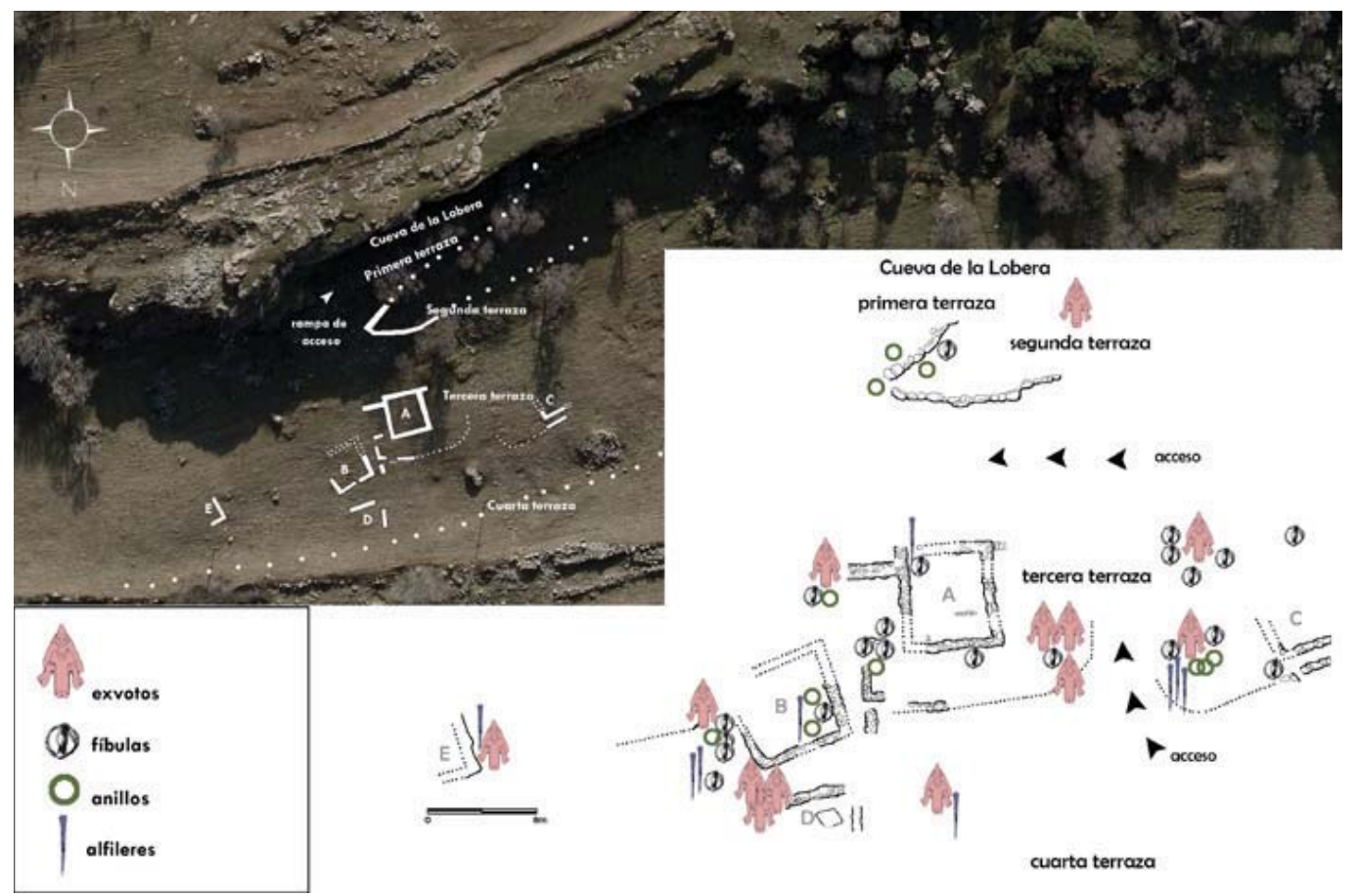

FIG. 5

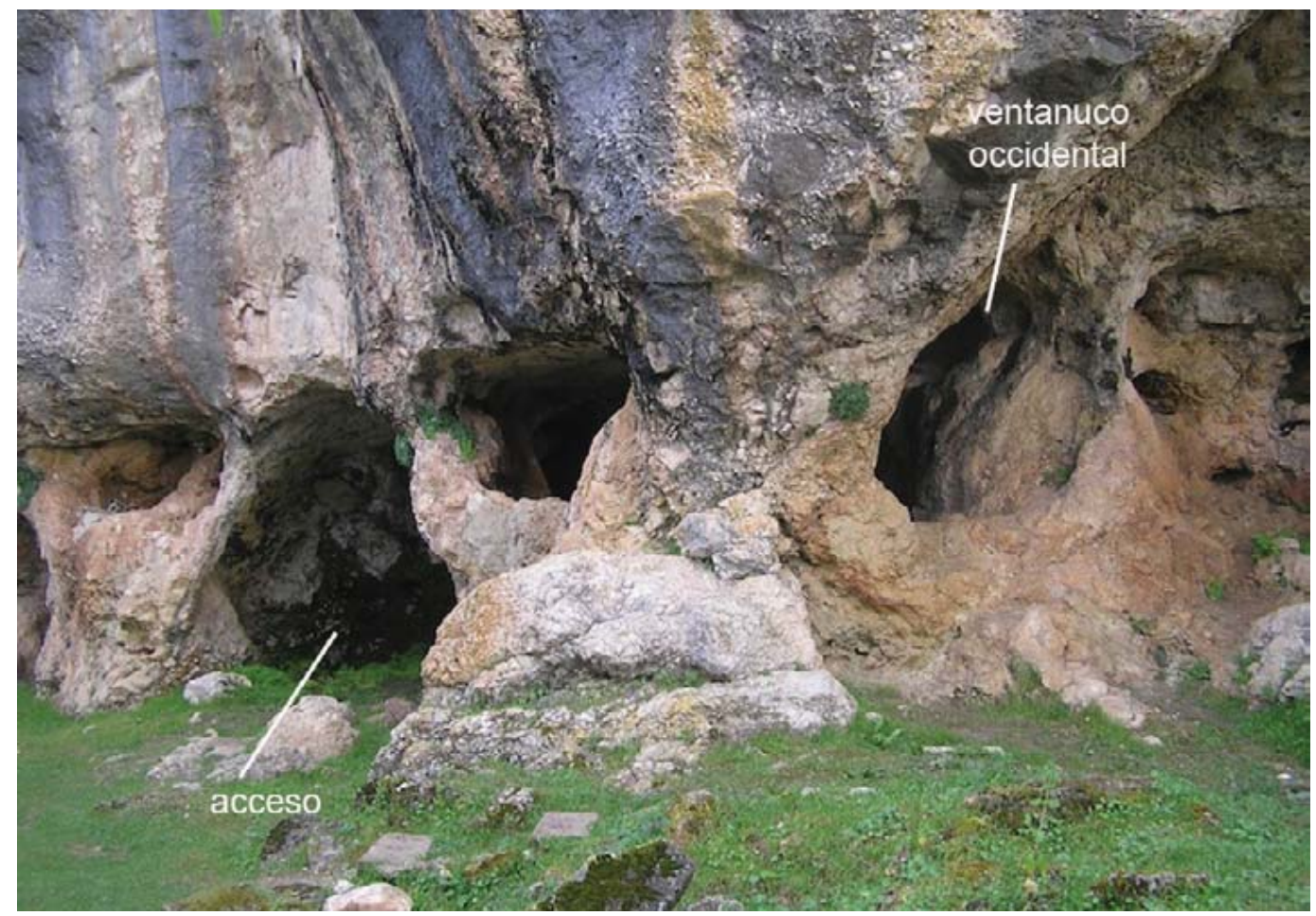

FIG. 6 
La Piedra del Águila se constituye como una cueva de $19 \mathrm{~m}$ de profundidad en la que es posible diferenciar distintas zonas. Un primer espacio lo conforma un corredor de $13 \mathrm{~m}$ de longitud y $3.5 \mathrm{~m}$ de anchura que funciona como área que articula funciones diversas. Por un lado, contribuye a organizar la entrada a la cueva que se realiza por el lado norte. De otro, en la zona sur, en el flanco pegado a la pared de la cueva, se han documentado varias estructuras, concretamente hogares rituales y depósitos de ofrenda de alimentos. De este corredor se pasa a una amplia sala central de 7 por $9 \mathrm{~m}$, en la que tenemos constancia (por excavaciones desarrolladas en los años 80) de la presencia de restos de ofrendas pero sin una lectura contextual adecuada (Fig. 8). Destaca la presencia, en el lado norte, de una sima de gran profundidad, y en la pared central de la misma, un orificio, a modo de hornacina, que es la huella de un manantial que discurriría, como una cascada, por la pared de fondo de la cueva. Este debió ser un elemento importante a nivel simbólico y ceremonial, ya que la presencia de turgencias de aguas subterráneas o de elementos naturales como estalactitas o estalagmitas recrea un espacio propicio para la construcción de mitologías, al mismo tiempo que son elementos que se integran en la liturgia. Evidencias de este argumento las ofrece este espacio de culto, en el que constatamos la presencia de estalagmitas recortadas de la propia cueva, las cuales fueron depositadas junto a las ofrendas de cerámica y alimentos.

La cueva como espacio multisensorial, que facilita planos emocionales y sensoriales 'no convencionales', se articula en una escenografía simbólica perfecta en el santuario de la Puerta sur de Puente Tablas. Merece la pena detenerse en este contexto, como ejemplo de cómo la cueva acerca el espacio liminal al oppidum, recreando otro tiempo mítico. Como se ha señalado ya, en este santuario urbano intervienen cuatro cuevas de pequeñas dimensiones. Tres de ellas se encuentran concentradas en la segunda terraza o terraza intermedia, una zona de desarrollo de rituales, concentrado en un patio abierto y enlosado, en el que se han documentado restos de ajuares votivos, entre el que destaca uno compuesto por crátera de figuras rojas y dos copas ${ }^{51}$. Los ritos con agua, purificada con azufre ${ }^{52}$, debieron jugar un papel importante en esta zona del santuario, unidos a la ofrenda de alimentos tales como cereales ${ }^{53}$. Destaca este patio, enlosado en dos niveles, siendo el más próximo a las cuevas el que recibe un tratamiento más cuidado, como el pavimento regular en el que destacan tres pequeñas piletas de libación que reproducen formas diferentes: la primera con

51. RUIZ ET AL.: "El santuario ibero...", 313-314.

52. PARRAS ET AL.: "Sulphur, fats...", 510-524.

53. MONTES, E.: "La agricultura y la gestión de los recursos vegetales en el oppidum de Puente Tablas", RUIZ, A., y MOLINOS, M. (eds.), Jaén, tierra ibera. 40 años de investigación y transferencia, Jaén, 2015, 127-136 (132-133). 


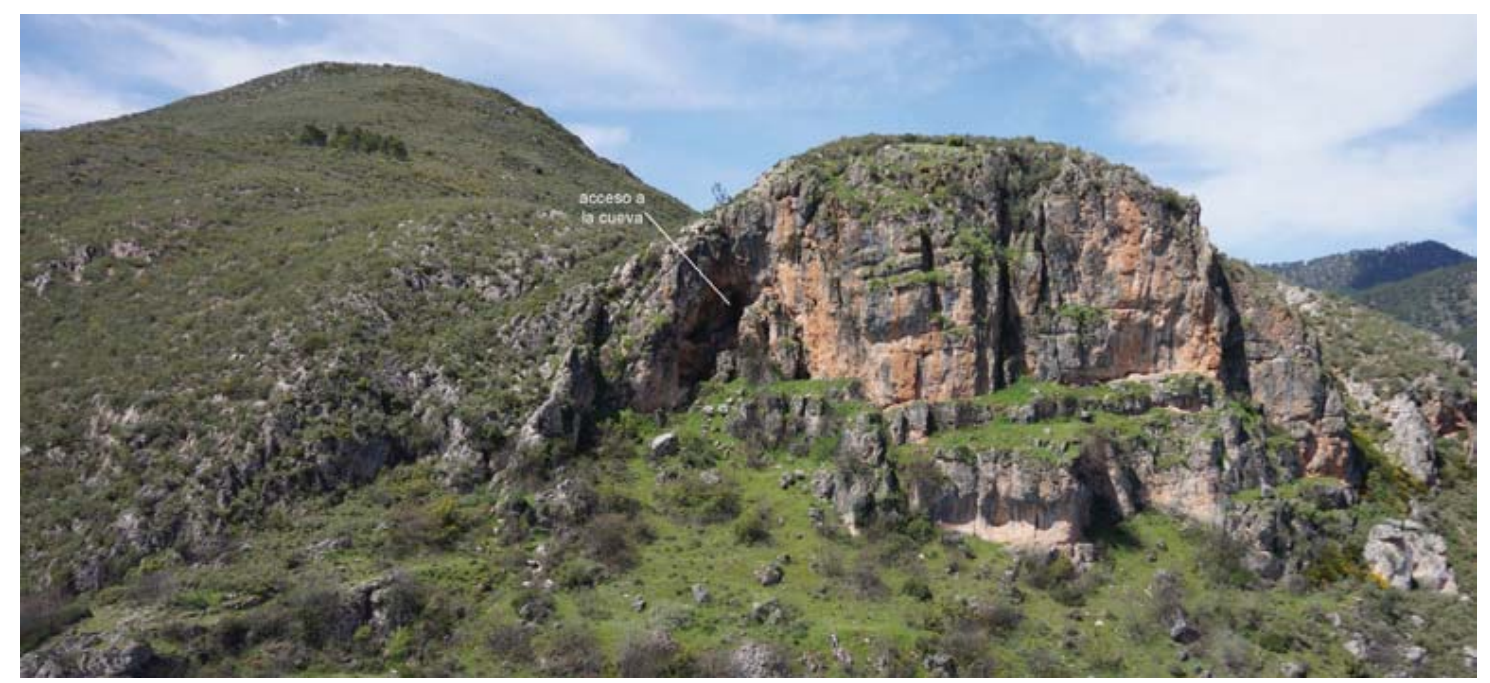

FIG. 7

forma de cuadrado; la segunda, tiene una forma almendrada, con un rebaje circular en el centro (que recrea un ojo); y la tercera, una forma circular con un canal lateral, que parece representar una oreja ${ }^{54}$ (Fig. 9). Cada uno de estos altares de libación se alinea con cada una de las tres cuevas, generando una relación inexcusable. Interesa remarcar cómo el témenos de estas cuevas se demarca por un tratamiento distinto y muy particular, generando un límite (límite entre lo urbano y lo salvaje, lo controlado no controlado...) demarcado por una línea de piedras clavadas en la tierra. Las cuevas no se enlosan ni se asocian a material arqueológico alguno, no hay huella humana en ellas.

Existe una conexión evidente entre el ritual y los sentidos implicados en el mismo, lo que se pretende oír, ver y lo que se anhela recibir, teniendo a la fe y a la esperanza como emociones que dominan las relaciones entre humanos y dioses ${ }^{55}$. A esto hay que añadir la cuarta cueva, que se localiza en otra área del santuario, separada de esta zona por una pared que evitaría que fuese vista desde las terrazas inferiores. Entran aquí en juego aspectos relacionados con la circulación ritual del santuario y la

54. RUIZ ET AL.: "El santuario de la Puerta...", 104.

55. CHANIOTIS, A.: "Emotional community through ritual: initiates, citizens and pilgrims as emotional communities in the Greek world", CHANIOTIS, A. (ed.), Ritual dynamics in the Ancient Mediterranean. Agency, emotion, gender, representation, Stuttgart, 2011, 263-290 (266). 


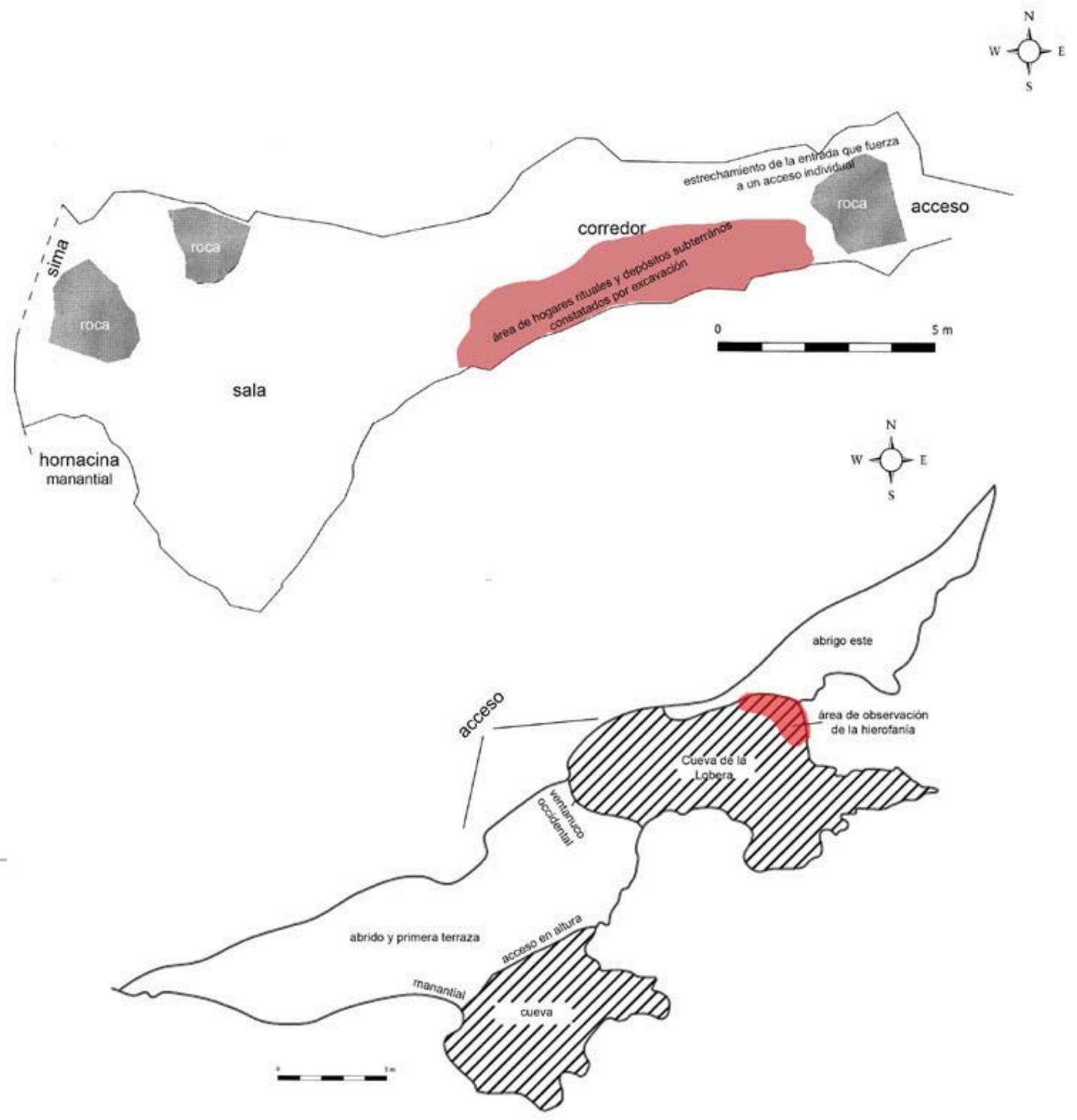

FIG. 8

dicotomía entre lo accesible y lo inaccesible. Es importante porque esta cueva se vincula a un episodio de la narración mitológica de este santuario, un efecto de carácter social restringido, de carácter aristocrático.

La introducción en estos espacios generadores de otros mundos y de otras dimensiones supone una ruptura de lo cotidiano que potencia una hipersensibilidad sensorial que es fortalecida por las distintas escenografías y por los recursos de accesibilidad. Una teatralización o performance que otorga solemnidad al hecho de transitar el espacio sagrado y que, sin duda, favorece a la conexión entre los sentidos y la 


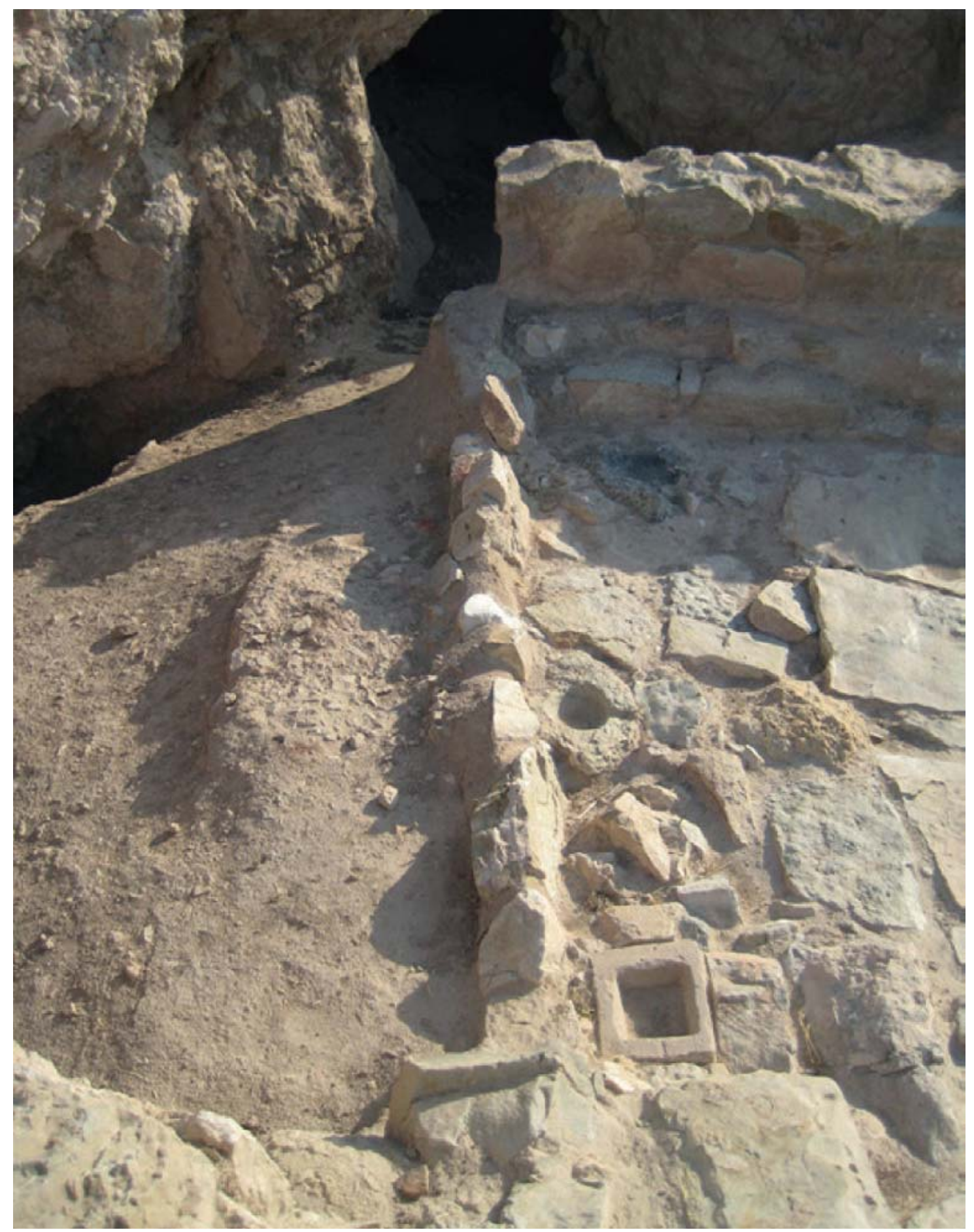

FIG. 9 
sacralidad del lugar. Y las emociones, que se constituyen en una relación cerrada e íntima entre el culto comunitario y la divinidad ${ }^{56}$, se canalizan a través del ritual y de la normativa litúrgica. La iconografía votiva es un campo de análisis muy sugerente para abordar cómo, a través de gestualidades y actitudes, se configura un lenguaje religioso que se sustenta, en gran parte, en los sentidos. La gestualidad religiosa asociada a prácticas rituales concretas permite esta lectura, teniendo en cuenta la 'asociación cuerpo-sentimiento ${ }^{57}$. De manera específica, el amplísimo corpus de exvotos de bronce de los santuarios giennenses nos introduce en los canales de expresión los sentidos y en los mecanismos sensoriales que se establecen en el contacto directo con la divinidad ${ }^{58}$. En la configuración de la imagen normativa de estos santuarios, codificada por preceptos litúrgicos que son asumidos por toda la comunidad, hay un claro interés por representar los anhelos de comunicación divina, con la implicación de sentidos corporales básicos. Así la mirada, que se proyecta en un plano en altura, posiblemente hacia la propia cueva ${ }^{59}$, como un recurso que evidencia la esperanza del contacto visual con la manifestación de lo sagrado que, desde otras aproximaciones arqueológicas, sabemos que se produce, en forma de hierofanía solar ${ }^{60}$. Otro sentido clave es el oído, representado en la hipertrofia de las orejas de los y las peregrinas, en una recreación del epékoos o atención a lo que la divinidad tiene que decir ${ }^{61}$, pues su fuerza creadora se manifiesta en el conjunto de sonidos producidos en estos santuarios de naturaleza abrupta. Y, por último, el tacto, manifestado en una prerrogativa religiosa presente en la mayor parte de las series de exvotos de estos santuarios: la representación de los pies descalzos. Se potencia así el contacto directo con el suelo sagrado (Fig. 10).

56. CHANIOTIS: “Emotional community...", 265.

57. IZQUIERDO, I.: "La colección de los exvotos femeninos ibéricos del Museo Valencia de Don Juan: gestualidad y género", MORENO-CONDE, M. (ed.), Exvotos Ibéricos. Vol, I: El Instituto Valencia de Don Juan, Jaén, 2006, 119-150.

58. PRADOS, L.: Exvotos ibéricos de bronce del Museo Arqueológico Nacional, Madrid, 1992; RUEDA: Territorio, culto....

59. RUEDA, C.: Exvotos Ibéricos. Vol, II: El Instituto Gómez-Moreno. Fundación Rodríguez-Acosta (Granada), Jaén, 2012, 141.

60. ESTEBAN, RÍSQUEZ y RUEDA: “Una hierofanía..., 91-107.

61. OLMOS, R.: "El coleccionista y el bronce: la ofrenda ibérica en los exvotos del Valencia de Don Juan”, MORENO-CONDE, M. (ed.), Exvotos Ibéricos. Vol, I: El Instituto Valencia de Don Juan, Jaén, 2006, 15-29 (24). 


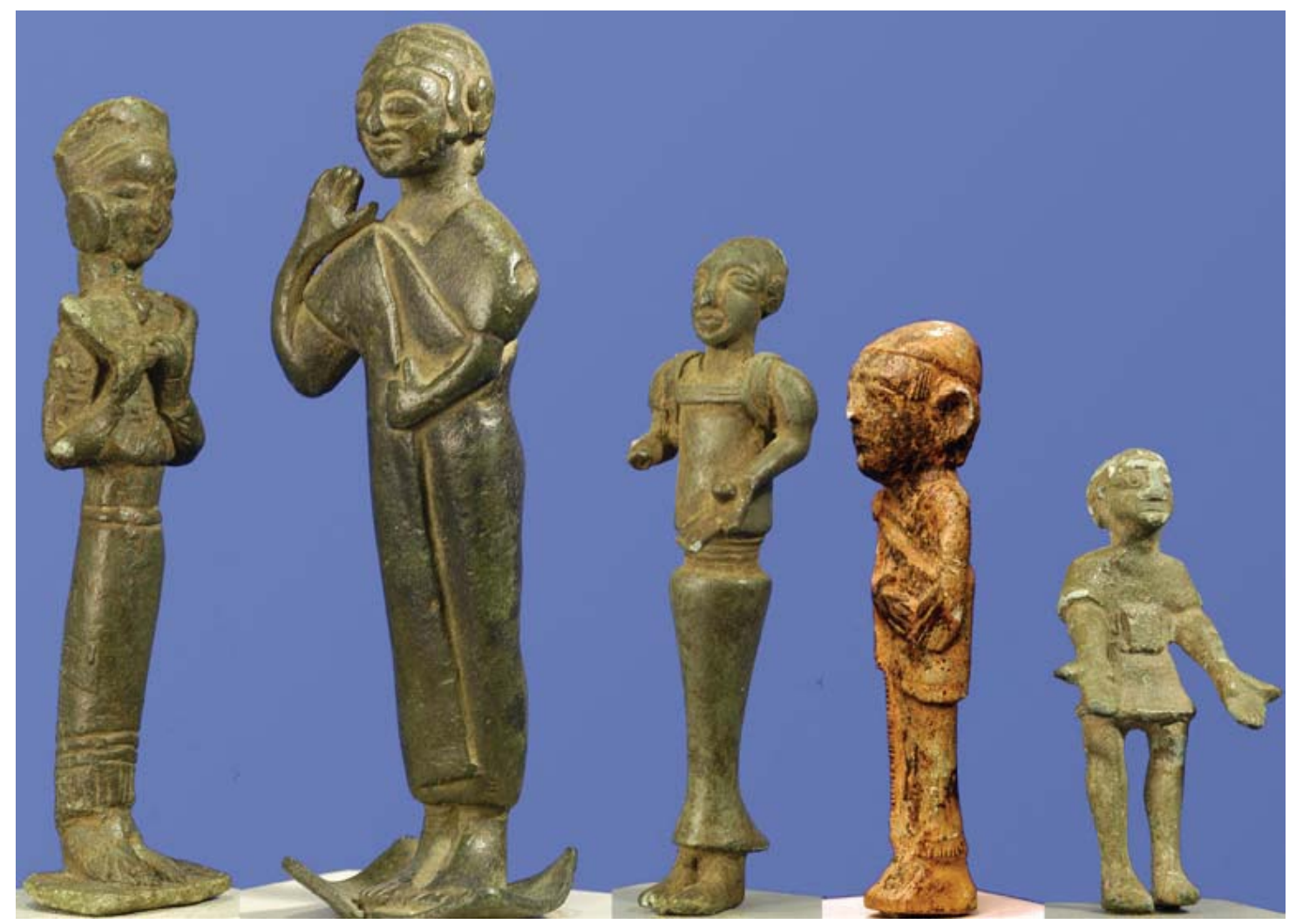

FIG. 10

\section{LA DIOSA Y LA CUEVA: HACIA LAS NARRACIONES MÍTICAS DIVINAS}

En la religiosidad ibera tenemos evidencias del uso de mecanismos de demostración visual de narrativas míticas asociadas a la divinidad femenina, costumbres religiosas que aportan y complementan la experiencia de la peregrinación y que resignifican a determinados santuarios como espacios especiales de manifestación de lo sagrado ${ }^{62}$.

La cueva se integra, simbólica y escenográficamente, como espacio sobredimensionado en las dinámicas visuales del mito y del rito y en la encarnación de lo invisible, como proceso que contribuye a objetivizar el fenómeno sagrado ${ }^{63}$, como ejercicio consciente $y$, fundamentalmente, compartido, pues la experiencia sensorial requiere de una materialidad que la potencie ${ }^{64}$. Las formas de manifestación utilizadas son heterogéneas, aunque en este trabajo vamos a fijar el foco de atención en los fenó-

62. ALFAYÉ: Imagen y ritual..., 157-158.

63. ALFAYÉ: Imagen y ritual..., 112.

64. ESTEBAN, RÍSQUEZ y RUEDA: “Una hierofanía...”, 104. 
menos astronómicos utilizados para la recreación de las narraciones míticas divinas, que adquieren un papel vital para la cohesión social, sobre todo en el desarrollo de los siglos IV-III a.n.e.

En el heterogéneo ámbito religioso ibero la deidad femenina aglutina en su imagen funciones y solicitudes diversas, así como controla distintos planos, lo que se expresa en la heterogeneidad de la iconografía divina como imagen protectora, pero también (aunque de forma más excepcional) como imagen temible. Este ideal en ocasiones se transmite a través de signos concretos que identifican a la divinidad intangible, como el ave, como animal mediador, partícipe del diálogo con la divinidad ${ }^{65}$. En otras, adquiere forma humana, como diosa nutricia, también como receptora en el inframundo, o como diosa relacionada con la naturaleza y la fecundidad de la tierra, en una acepción que sufre un desarrollo importante a partir del siglo III a.n.e. ${ }^{66}$.

Además, la divinidad ibera tiene un importante componente astral que puede ser seguido en su relación astronómica en números espacios de culto, dentro o fuera de los asentamientos, y los equinoccios son eventos claves en esta relación ${ }^{67}$. Una relación entendida y medida por los ciclos naturales y agrarios, como procesos que contribuyen a la ritualidad, a la rememoración estacional de esos mitos vinculados a la divinidad femenina. Según César Esteban, más que hablar de equinoccios, habría que referirse a conceptos próximos al 'día mitad', como esquema de medición temporal que no es otra cosa que el punto medio temporal entre solsticios, que puede ser fijado de manera más precisa por el posicionamiento extremo del astro solar sobre la bóveda celeste, momento en el que se produce una diferencia mayor entre las horas diurnas y nocturnas ${ }^{68}$. En estos procesos puede estar la clave para la medición temporal, en ciclos anuales, para fijar el momento que actualmente identificamos con los equinoccios. Por otra parte, guarda la coherencia de la percepción del tiempo en la antigüedad: el eterno retorno, el ciclo mítico es repetido y constante, necesariamente estático para garantizar su propio relato.

Rito, equinoccio, cueva y divinidad femenina cuentan con un excepcional ejemplo de asociación y desarrollo en el santuario de la Puerta del Sol de Puente Tablas. En este caso y como se ha avanzado, la imagen divina se representa en una estela de

65. OLMOS, R., y TORTOSA, T.: “Aves, diosas, mujeres", CHAPA, T., e IZQUIERDO, I. (eds.), La dama de Baza. Un viaje femenino al más allá, Madrid, 2010, 243-258.

66. OLMOS, R.: "El lenguaje de la diosa de los pebeteros. Signo icónico y función narrativa en dos tumbas de La Albufereta (Alicante)", MARÍN CEBALLOS, M.C., y HORN, F. (eds.), Imagen y culto en la Iberia prerromana: los pebeteros en forma de cabeza humana, Sevilla, 2007, 367-390.

67. ESTEBAN, C.: "Arqueoastronomía y religión ibérica", RÍSQUEZ, C., y RUEDA, C. (eds.), Santuarios Iberos: territorio, ritualidad y memoria. Actas del Congreso El santuario de La Cueva de la Lobera de Castellar. 1912-2012, Jaén, 2013, 465-484 (480).

68. ESTEBAN: “Arqueoastronomía..., 475. 
piedra, someramente tallada, en la que se indican algunos rasgos concretos, como los brazos esculpidos que apoyan en el vientre y las manos entre abiertas que enmarcan un elemento circular. Otros elementos definen el carácter y género de esta imagen puesto que, aunque carece de rostro, posee signos que la definen como una imagen femenina, como la tiara apuntada, el velo abierto que cae y se recoge en el lateral derecho de la imagen o el manto cruzado, que pende del hombro izquierdo (Fig. 11). Se ha interpretado como una divinidad femenina, que recoge aspectos coincidentes con otras representaciones coetáneas, como la del excepcional mosaico de la necrópolis de Cerro Gil (Iniesta, Cuenca) ${ }^{69}$. Esta imagen ocupaba, en días claves del calendario ritual, un lugar privilegiado en el exterior del santuario, perfectamente alineada con el corredor de la puerta del oppidum, en una escenografía planificada ya que en el orto del equinoccio el sol se orienta perfectamente con dicho corredor, provocando la iluminación de la diosa que sale de la penumbra que produce la estructura de la puerta. Esta hierofanía solar teatralizada se desarrolla durante unos minutos, hasta que la sombra que proyecta la puerta oscurece de nuevo esta imagen. En este momento se produce un movimiento que hace que este fenómeno deje de ser una hierofanía para crear un discurso mítico, puesto que el sol gira y penetra en el fondo de la cuarta cueva, generando una imagen alargada, que va desapareciendo paulatinamente. Este proceso es perceptible durante ocho jornadas, es decir, el evento del equinoccio determina la duración de las celebraciones, aunque la propia construcción de la puerta y de elementos arquitectónicos vinculados al santuario, como la capilla, nos introducen en un posible calendario ritual más complejo, que articularía los ritos asociados a diferentes momentos del año ${ }^{70}$.

Interesa, en relación a la implicación de la colectividad en el rito y en relación a la explicación del mito, cómo los distintos momentos de esta narración visual demarcan las formas en que puede ser observado. De esta forma, el proceso de iluminación de la escultura que representa a la divinidad se produce en un exterior que, si bien en el entorno inmediato es limitado, puede ser observado desde diferentes puntos del oppidum. Distinta es la situación en la cuarta cueva del santuario, un espacio resguardado y de acceso bastante restringido, al que posiblemente solo unos pocos -los vinculados directamente en el ritual- podrían tener acceso.

La explicación de la narración del mito vinculado a este santuario, que articula la imagen en piedra con la cueva y diferentes elementos y áreas arquitectónicas, es complicada, aunque en nuestra opinión estos reconstruyen la secuencia de un mito

69. GONZÁLEZ REYERO, S.: "Antepasados y grupos aristocráticos. Memorias de inclusión y de exclusión entre los iberos", GONZÁLEZ-REYERO, S. (ed.), Iberos. Sociedades y territorios del occidente mediterráneo, Madrid, 2012, 103-119 (110).

70. RUIZ ET AL.: “El santuario ibero...”, 309-319.

ARYS, 14, 2016 [43-80] ISSN 1575-166x 


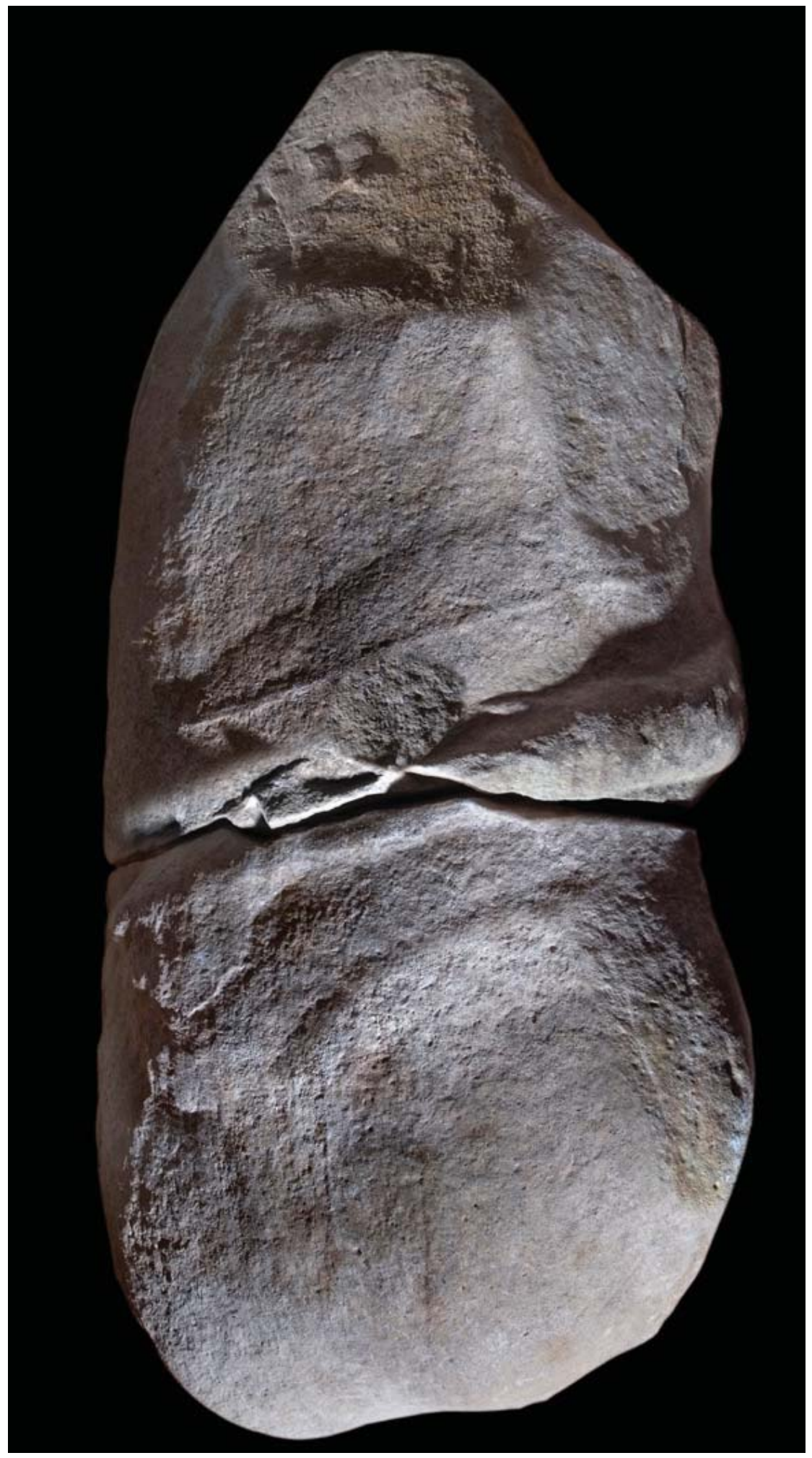

FIG. 11 
que se basa en la relación sol-diosa, que narra una acción en la que la divinidad accede a la cueva ante la vista de los elegidos y que puede tener una doble interpretación: de un lado, la epifanía y de otro, la hierogamia, pues el mito, en esta fase, parece describir dinámicamente el viaje de la diosa para encontrar y recuperar a su paredro o, más bien, a un héroe, como figura habitual en la mitología ibera ${ }^{71}$. Este mito permanece vigente para la ritualidad de esta ciudad ibera hasta mediados del siglo IV a.n.e., momento en el que el santuario sufre fuertes reestructuraciones que comportan la inutilización de áreas claves como las cuevas, y de elementos sobre los que se sustentaba la ritualidad, como la estela antropomorfa, que fue sepultada, parece ser que de manera intencionada, delante de la puerta de este espacio de culto.

El segundo caso que exponemos, documentado en el santuario de La Cueva de la Lobera, nos introduce en fenómenos que juegan con la iluminación solar, con un fuerte carácter simbólico, vinculados a la propia arquitectura natural, lo que ha llevado a definirse como 'marcadores en cueva' ${ }^{\text {' }}$, fenómenos que dotan de función cultual a la cueva. En este santuario se potencia un prodigio que se desarrolla en la cueva como espacio central, asociado al ocaso de los equinoccios. El mismo se produce en la cueva que ocupa el extremo este del farallón, en la que, como se ha indicado anteriormente, existe un ventanuco (en su pared oeste) que conecta, con una orientación casi perfecta este-oeste, con la zona más profunda del interior. Durante los equinoccios, los últimos rayos solares del día se introducen a través de esta apertura y se proyectan en el fondo de la cueva, iluminando esta área y conformando una imagen visual que simula el estereotipo propio de la imagen femenina en este santuario y que también se ha interpretado como una epifanía/hierofanía ${ }^{73}$ (Fig. 12).

Es importante indicar que la escenificación está construida, en la medida de que el ventanuco citado está retocado de manera artificial, comprobándose cómo la propia apertura determina algunos de los rasgos más relevantes de la hierofanía (como el tocado apuntado) y que coinciden aún hoy con una zona ahuecada del interior de la cueva. Lo que se observa en la actualidad debe corresponderse en gran medida con lo que se producía en los siglos IV-III a.n.e. ${ }^{74}$.

Este prodigio nos sitúa ante los mecanismos empleados para las recreaciones visuales de lo sagrado, en concreto en cómo este tipo de experiencias se construyen y reviven en el conjunto de las identidades colectivas, ya que en ellas median categorías sociales de identificación y clasificación que son entendidas en el marco de la comunidad religiosa. Por otro lado, nos introducen en aspectos clave de aproximación a los calendarios rituales, pero también a los tiempos del rito, ya que el hecho de que

71. RUIZ ET AL.: "El santuario ibero...”, 317.

72. ESTEBAN: “Arqueoastronomía...”, 472.

73. ESTEBAN, RÍSQUEZ y RUEDA: "An evanescent vision...”, 99-106.

74. ESTEBAN, RÍSQUEZ y RUEDA: “Una hierofanía...”, 98-99. 
el fenómeno de la hierofanía se desarrolle al ocaso (prolongado durante unos días), demarca toda una jornada de celebraciones, de manera que ésta se cierra y termina al anochecer.

Por otro lado, acerca de la perduración de estos procesos religiosos es necesario remarcar cómo, en los dos casos expuestos (Puente Tablas y Castellar), adquieren sentido en un contexto político y social concreto, constatándose el momento en el que se 'desmontan' o pierden valor coincidiendo con etapas de fuertes transformaciones. En el caso de Puente Tablas, como se ha indicado, esta narración mítica, tan fuertemente enraizada al culto aristocrático, sirve de justificación a un modelo político-religioso que no se prolonga más de setenta y cinco años. Respecto al santuario de Castellar, aunque el fenómeno se ha conservado sin que se puedan constatar, a diferencia de lo que sucede en el oppidum giennense, procesos de transformación directa de la escenografía o de la arquitectura, intuimos que debió caer paulatinamente en desuso y en el olvido desde inicios del siglo II a.n.e. Esta fecha marca el inicio de un proceso de control ideológico de estos espacios de culto, vinculado a los cambios políticos que fuerzan a la desestructuración del gran territorio político de Cástulo ${ }^{75}$. En ese santuario, al igual que en Collado de los Jardines, el recuerdo de la deidad de tradición se va desdibujando con la incorporación de deidades del panteón romano, como Minerva, Mercurio y Venus ${ }^{76}$.

Frente a estos procesos, contamos con casos que evidencian la proyección de la divinidad femenina en el territorio, en su vinculación como diosa asociada a la cueva, como espacio liminal. Un reciente trabajo nos introduce en un ejemplo muy ilustrativo y sugerente en el que se constata el proceso de continuidad y de rememoración simbólica, como mecanismos fundamentales para la articulación y apropiación de los territorios políticos. Así, el santuario de La Umbría de Salchite, se convierte en un marcador religioso clave en un territorio, en una referencia para las políticas de reordenación territorial post Segunda Guerra Púnica. Las variables analizadas en los casos expuestos se reiteran en este espacio de culto en cueva. Así, se define -al igual que Castellar- como marcador en cueva al que se asocian fenómenos astrológicos vinculados al ocaso en los solsticios de invierno ${ }^{77}$. A él también se vincula la iconografía femenina, constatado a través de un excepcional ejemplar de pintura vascular en la que se conserva una imagen interpretada como una divinidad de aspecto terrorífico, en el que destacan los brazos acabados en prótomes de lobos. Una deidad ctónica

75. RUEDA, C., y RUIZ, A.: "Modelos cultuales a contraste: estrategias de 'continuidad' en los santuarios territoriales del Alto Guadalquivir (finales del siglo III a.n.e.-finales del I a.n.e.)", TORTOSA, T., y RAMALLO, S. (eds.), El tiempo final de los santuarios ibéricos en los procesos de impacto y consolidación del mundo romano, Madrid, en prensa.

76. RUEDA: Territorio, culto..., 139-143.

77. ESTEBAN: “Arqueoastronomía..., 473. 

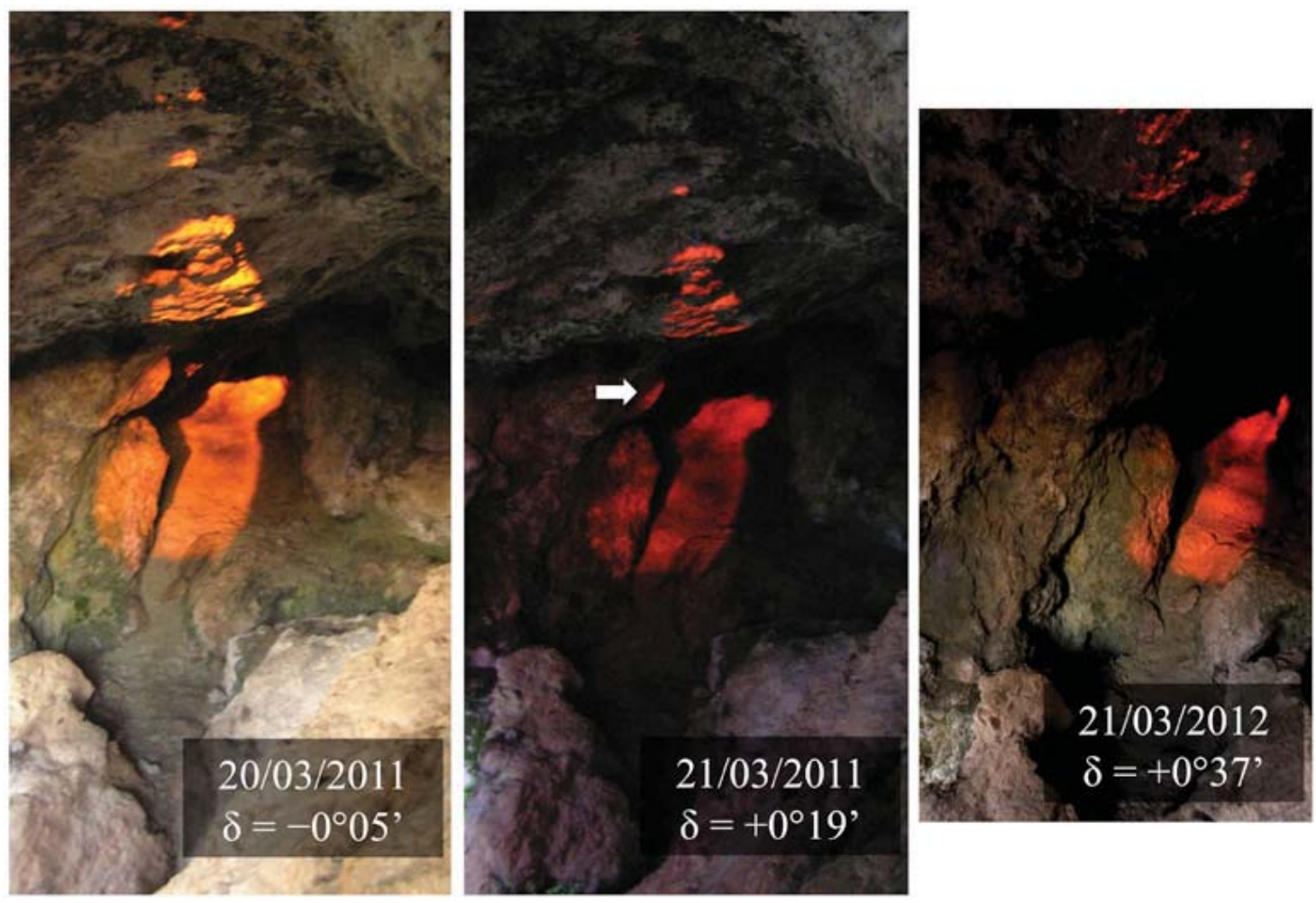

FIG. 12

vinculada a la cueva que se recrea en la propia iconografía como espacio confrontado con el exterior, y asociada al fuego y, en concreto, a un elemento clave en el ritual, como es el brasero o el morillo. Este instrumental se convierte en un marcador territorial, pues se documenta en varios asentamientos, como Molinicos, desde el siglo IV a.n.e., vinculándose simbólicamente a la imagen femenina que acompaña a algunos ejemplares. La imagen femenina presente de manera diacrónica en este territorio y en su santuario comunitario y su vinculación a prácticas rituales protagonizadas por la presencia del fuego y de instrumental recurrente que aparece en la iconografía y en el registro material, son claves para armar la propuesta de la continuidad del relato mítico relacionado con la divinidad femenina ( con el fuego y con la cueva) en el que pudieron mediar transmutaciones y readaptaciones a realidades sociales y políticas nuevas, en las que el santuario en cueva, como lugar central, siguió teniendo un significado determinante para las comunidades de este territorio ${ }^{78}$. 


\section{LOS PROCESOS RITUALES COMO MECANISMOS DE GESTIÓN DEL MIEDO}

El culto ibero, como amplio conjunto de ritos y ceremonias, posee recursos de plasmación diversos, relacionados asimismo con aspectos múltiples y con deidades con variantes definidas. El rito se materializa en 'artefactos e imágenes' que lo definen como instrumentos activos pero también en pautas de comportamiento que dejan huella perceptible en el registro arqueológico. Gracias a la definición de estos esquemas litúrgicos es posible aproximarnos a las motivaciones del ritual y a determinadas emociones humanas vividas desde lo individual y lo colectivo, como el miedo, como necesidades de orden primario que requieren de mecanismos de 'satisfacción' frente a esa percepción del peligro, del riesgo, de lo desconocido. El análisis arqueológico del ritual religioso como instrumento de gestión de los miedos es una perspectiva que aporta nuevas miradas a la funcionalidad del rito como dispositivo de control social, pero sin perder de vista la vertiente que lo vincula a las emociones y a los temores más básicos. Los santuarios son espacios fabricados para gestionar las emociones, para satisfacer multiplicidad de deudas/peticiones en el diálogo entre lo humano y lo divino. Proponemos abordar estas cuestiones desde ritualidades diferentes que comparten como espacio de desarrollo los santuarios en cueva, exponiendo casos concretos que pueden ilustrar y enriquecer el tema.

\section{A. LA FUERZA SANADORA DE LA COMUNIDAD: LAS PRÁCTICAS DE AGREGACIÓN.}

La pertenencia a una comunidad religiosa sirve de engranaje identitario de gran valor y se manifiesta, entre otras formas, en la asunción de un conjunto de procesos rituales que vienen determinados por las acciones del propio grupo y que están motivadas por expectativas favorables o de éxito a nivel social, lo que da sentido a las propias experiencias colectivas. Los valores que rigen estas experiencias religiosas se integran en una cosmovisión que ayuda y contribuye a la organización del grupo ${ }^{79}$. Un caso muy ilustrativo es el del territorio de Cástulo que engloba a diferentes linajes de los oppida bajo un orden simbólico y religioso común. Una estrategia de cohesión compartida, que en parte se sustenta en comportamientos rituales asumidos y en normativas que son observables en el propio registro votivo, por ejemplo, en el uso de un determinado instrumental litúrgico o en la utilización de categorías votivas compartidas, pero también en celebraciones de tipo colectivo, como el consumo compartido del banquete ritual. Asimismo en formas de expresión y de relación con el espacio sagrado que nos sitúa ante comportamientos internos de la comunidad religiosa consigo misma. De este modo, la homologación del gesto se vincula al reco-

79. GARCÍA, M.: "Rituales de paso y categorías sociales en la migración internacional nahua del Alto Balsas, Guerrero", Cuicuilco, 25, 42, 2008, 77-96. 
nocimiento de la pertenencia a una comunidad religiosa, como lenguaje compartido entre el colectivo y la divinidad que, en el caso de los santuarios de Cástulo, queda perfectamente fijado a través de numerosas series de exvotos en bronce en los que se repiten y reiteran estos rasgos gestuales.

\section{B. EL PODER DE LA RITUALIDAD PARA LA TRANSFORMACIÓN: LOS RITOS DE PASO}

Bajo la definición genérica de 'ritos de paso' se enmarcan toda una serie de prácticas que simbolizan el tránsito de un estadio a otro, todo ello justificado dentro de una estructura simbólica y religiosa específica. En ocasiones son entendidas como ritualidades que cumplen una función social y, por ello, se desarrollan en el marco de la celebración comunitaria ${ }^{80}$. Poseen un rasgo que las define: la 'no reedición' que comporta que el ritual se presenta una única $\mathrm{vez}^{81}$.

Los ritos de paso también enmarcan procesos de negociación o reafirmación de competencias dentro de la estructura de poder ${ }^{82}$. Este aspecto es perceptible en el santuario de la Puerta del Sol de Puente Tablas, donde los ritos de iniciación, vinculados a la esfera aristocrática, debieron jugar un papel importante en su función ritual. Los ritos de iniciación se definen en la escena representada en la crátera de campana que se localiza, como parte de un ajuar ritual, delante de las cuevas de este santuario. El protagonista de esta representación es un joven que recibe, de un hombre barbado que se dispone a su lado, una rama florida. Se sanciona, de esta manera, una jerarquía de edad fundamental para el desarrollo del rito de paso. La escena debió completarse con otro personaje masculino que quedaría dispuesto a la izquierda del joven y del que se conserva parte del cabello. Esta representación se enmarca en un espacio sacro, que queda limitado por ornamentos como el bucráneo decorado con guirnaldas, y se ratifica por la estatua de la divinidad -posiblemente Afrodita o Artemis- a acompañada por sus atributos, como un tocado destacado rematado por un elemento que definimos como estrella o astro ${ }^{83}$.

Por otro lado, en los santuarios de Collado de los Jardines y La Cueva de la Lobera estas prácticas se integran como ritualizaciones de etapas fundamentales del ciclo vital, claves en el aprendizaje social ${ }^{84}$. De nuevo los exvotos de bronce se convierten en una fuente iconográfica importante para analizar un conjunto de prácticas

80. VAN GENNEP, A.: Los ritos de paso, Madrid, 1986.

81. GARCÍA: "Rituales de paso..., 77-96.

82. GARCÍA: "Rituales de paso...", 77-96.

83. RUIZ ET AL.; "El santuario ibero...", 309-319.

84. RUEDA, C.: "Ritos de paso de edad y ritos nupciales en la religiosidad ibera: algunos casos de estudio", RIISQUEZ, C., y RUEDA, C. (eds.), Santuarios Iberos: territorio, ritualidad y memoria. Actas del Congreso El santuario de La Cueva de la Lobera de Castellar. 1912-2012, Jaén, 2013, 341-383. 
que tienen amplia visibilidad en estos espacios de culto y que se vinculan con el ciclo biológico, como los ritos de paso de edad, los ritos nupciales, los ritos de fertilidad y fecundidad o los ritos de gestación, pero también con otras ritualidades de carácter transversal, como los ritos de iniciación guerrera ${ }^{85}$. El rito, en todos estos contextos, da un marco institucionalizado que dota de reglas de aprendizaje social.

\section{LOS RITOS CURATIVOS: CANALIZACIÓN DEL MIEDO A LA ENFERMEDAD Y AL DOLOR}

Dentro del amplio abanico de las peticiones relacionadas con necesidades de orden primario un grupo importante, presente en algunos santuarios analizados como Castellar y Despeñaperros, se relaciona con rituales curativos. El miedo al dolor, la enfermedad o la muerte requiere de mecanismos de subsanación que se integran en la ritualidad de estos santuarios. Potencian el diálogo directo con la divinidad y se insertan en el espacio cultual, asociados a componentes naturales sugerentes como la presencia de manantiales, que formarían parte indispensable de la liturgia ${ }^{86}$.

Los canales de satisfacción, en los casos analizados, se materializan en la ofrenda de exvotos específicos para tal fin: los exvotos anatómicos, los cuales se asocian al concepto de sustitución y expiación ${ }^{87}$, en el que media la representación simbólica del órgano en sí, más que de la parte dañada, sustituyéndolo por la ofrenda a cambio de la sanación. Bien sea como promesa a cambio del favor, como regalo por el bien concedido o como recurso de satisfacción psicológica alcanzado a través del ofrecimiento $^{88}$, el corpus de exvotos anatómicos documentados en los santuarios giennenses es muy amplio, contando con categorías heterogéneas que hacen referencia a dolencias concretas. Así, forman parte de los depósitos votivos de estos santuarios, aunque mayoritariamente procedentes de Collado de los Jardines, exvotos con formas de pies, piernas, brazos, ojos, dentaduras, falos, pechos y úteros. Interesa destacar, por lo excepcional en el registro votivo ibero, cómo la presencia de exvotos de

85. RUEDA: Territorio, culto..., 154-155; PRADOS, L.: “¿Por qué se ofrecían los exvotos de recién nacidos? Una aproximación a la presencia de "bebés enfajados" en el santuario ibérico de Collado de los Jardines (Santa Elena, Jaén, España)", RÍSQUEZ, C., y RUEDA, C. (eds.), Santuarios Iberos: territorio, ritualidad y memoria. Actas del Congreso El santuario de La Cueva de la Lobera de Castellar. 1912-2012, Jaén, 2013, 325-339.

86. OLMOS, R.: “Iconografía y culto de las aguas de época prerromana en los mundos colonial e ibérico", Espacio, Tiempo y Forma, Serie II, Historia Antigua, 5, 1992, 103-120.

87. MONEO, T.: Religio ibérica: santuarios, ritos y divinidades (siglos VII-I a.C.), Madrid, 2003, 392.

88. PRADOS, L.: "Los exvotos anatómicos del santuario de Collado de los Jardines (Santa Elena, Jaén)”, Trabajos de Prehistoria 48, 1991, 313-332 (326). 
útero se relaciona con evocaciones a la maternidad ${ }^{89}$, pero también puede ponerse en relación con rituales de protección, y también de curación de las afecciones derivadas del parto o vinculadas a la etapa de puerperio ${ }^{90}$ (Fig. 13).

\section{Ritos de CARÁCTER AGRÍCOLA: LA OFRENDA DE ALIMENTOS EN LAS ENTRAÑAS DE LA CUEVA}

Para finalizar incluimos ritualidades relacionadas con aspectos de protección propiciación de la fecundidad de la naturaleza. Los ritos de carácter agrícola también se vinculan a estos espacios liminales, sin duda regidos por las pautas cíclicas propias del ámbito natural y por prescripciones específicas relacionadas con estas motivaciones, como la ofrenda de alimentos.

Sobre la ofrenda de alimentos en santuarios en cueva contamos con limitaciones que parten de un registro parcial y antiguo ${ }^{91}$. No obstante, las recientes excavaciones llevadas a cabo en la Piedra del Águila nos aportan datos sobre comportamientos rituales relacionados con el entorno territorial y con el ámbito natural. En este espacio de culto en cueva se ha documentado parte de la ritualidad, que conllevaba la ofrenda, en cantidades destacables, de alimentos vegetales. A partir de un registro con un estado de conservación excepcional y de los análisis paleoambientales nos hemos aproximado a la combinación de especies que conforman 'el menú' de ofrendas, compuesto por cebada vestida, trigo, haba y guisante y, en menor medida, mijo y avena. La Piedra del Águila se convierte, en esta dirección, en un contexto de relaciones simbólicas muy interesante, en el que la cueva no interviene exclusivamente como tesauro, sino que funciona como espacio en el que lleva a cabo gran parte de la cadena litúrgica. En este contexto, los rituales se desarrollan de manera íntegra al interior de la cueva, en los que el fuego interviene como elemento clave para la purificación, al mismo tiempo que para la conservación de la ofrenda (Fig. 14).

Las excavaciones han permitido reconstruir parte de la formalización de esta ritualidad, canalizada a través de la realización de hogares rituales en los que se queman (carbonizan) las ofrendas, depositadas en vasos cerámicos y en contenedores de esparto. A las ofertas vegetales, que se reiteran en todos los depósitos analizados, acompañan de manera puntual ofrendas animales, pero que en este caso no pasan por el fuego, sino que son depositadas una vez que el proceso de quemado ha finalizado. El proceso de

89. PRADOS: “PPor qué se ofrecían...”, 335.

90. RUEDA, C. ET AL.: Las edades de las mujeres iberas. La ritualidad femenina en las colecciones del Museo de Jaén, Jaén, 2016, 34.

91. No obstante, contamos con referencias interesantes y novedosas que contribuyen a reconstruir cómo intervienen este tipo de ofrendas en el culto asociado a cuevas. Ver, entre otras, MACHAUSE, S. ET AL.: "Prácticas rituales ibéricas en la Cueva del Sapo (Chiva, Valencia): más allá del caliciforme", Zephyrus, 74, 2014, 157-179.

ARYS, 14, 2016 [43-80] ISSN 1575-166X 
carbonización de los vegetales, sin ninguna duda, intencionada y controlada, asegura la preservación de la estructura del grano, un proceso buscado, pues el depósito final de los restos de estos rituales son fosas excavadas en el suelo de la propia cueva. Un recurso de satisfacción posiblemente orientado a 'alimentar' a la divinidad, para que ella provea sobre el futuro de la próxima cosecha. Rituales y pautas de comportamiento simbólico que se caracterizan por reiterarse en el tiempo y en un mismo espacio, a modo de comportamientos cíclicos vinculados al calendario agrícola.
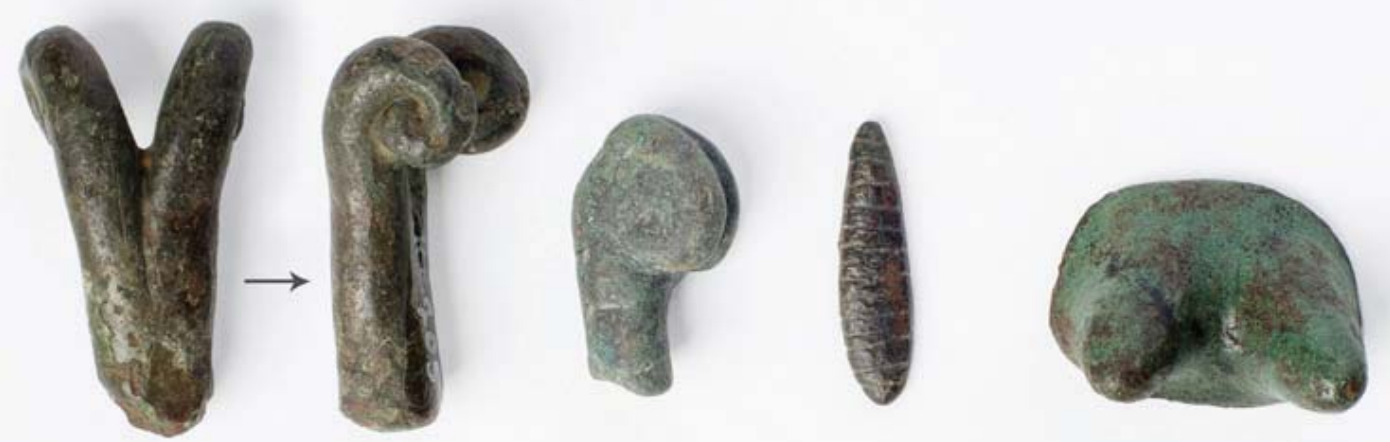

FIG. 13 

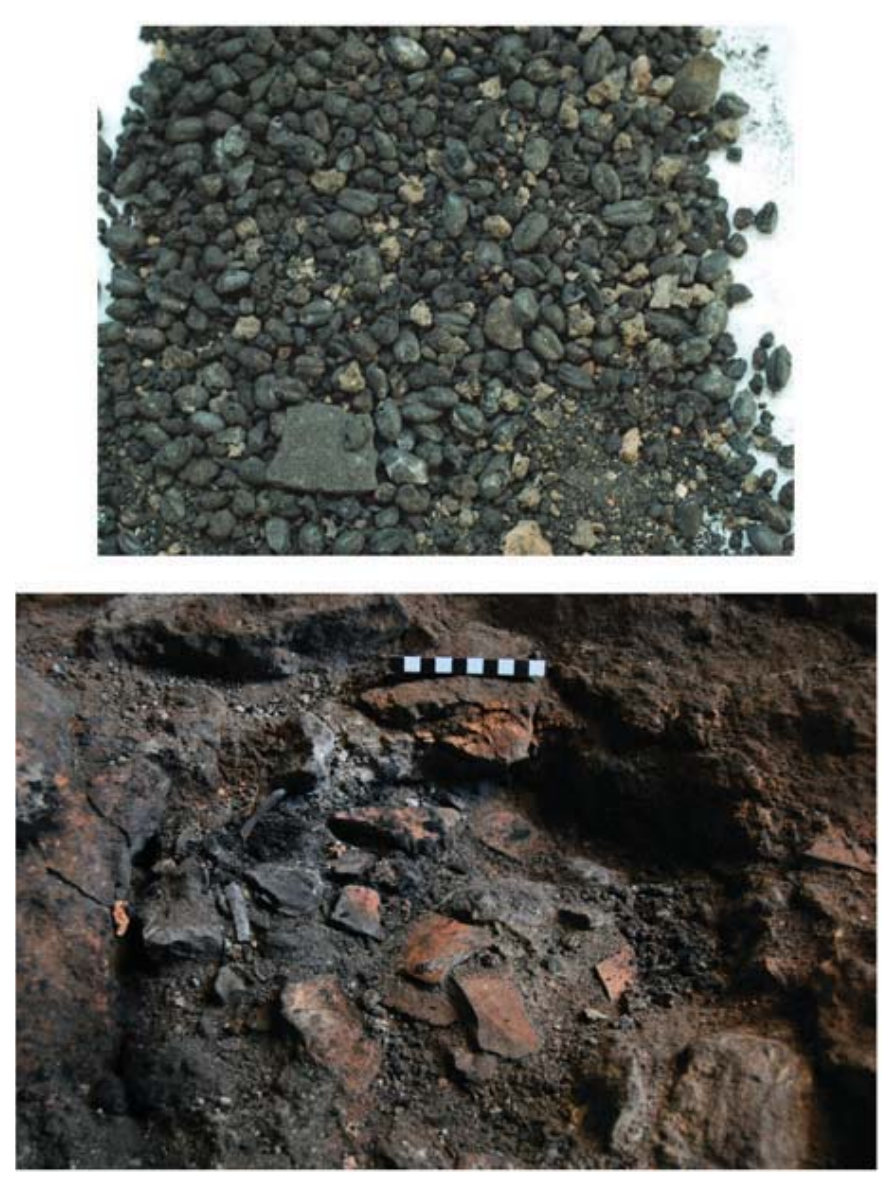

FIG. 14
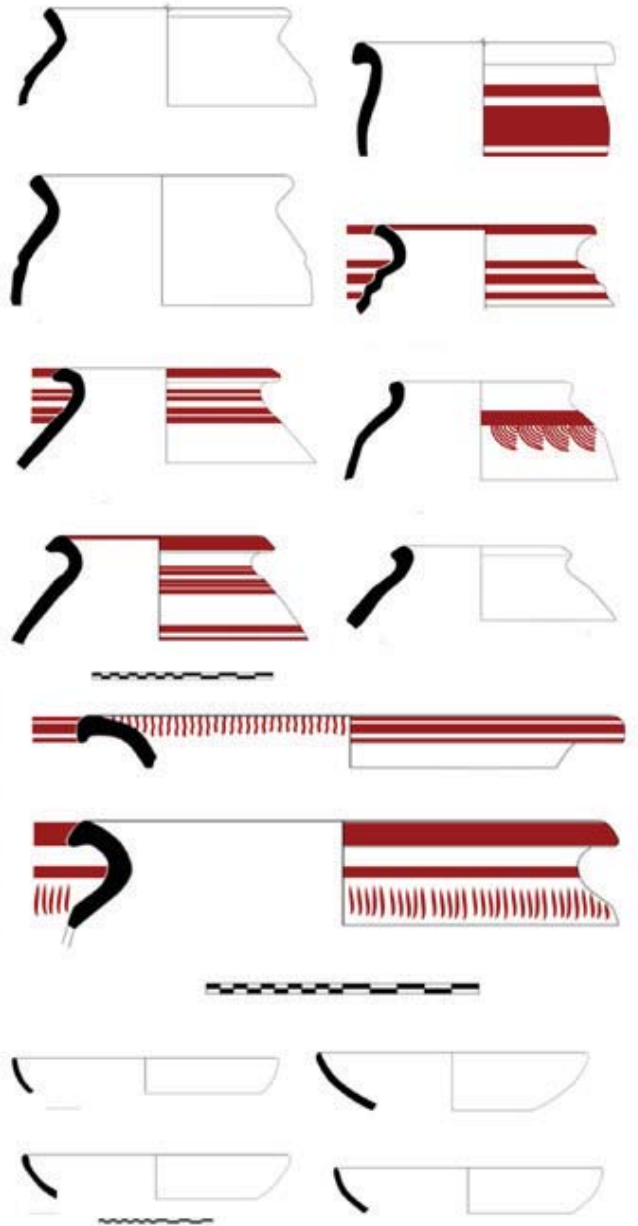